\title{
BMJ Open Antibiotics for uncomplicated skin abscesses: systematic review and network meta-analysis
}

\author{
Wen Wang, ${ }^{1}$ Wenwen Chen, ${ }^{1}$ Yanmei Liu, ${ }^{1}$ Reed Alexander C Siemieniuk, ${ }^{2,3}$ \\ Ling Li, ${ }^{1}$ Juan Pablo Díaz Martínez, ${ }^{4}$ Gordon H Guyatt, ${ }^{2}$ Xin Sun ${ }^{1}$
}

To cite: Wang W, Chen W, Liu Y, et al. Antibiotics for uncomplicated skin abscesses: systematic review and network meta-analysis. BMJ Open 2018;8:e020991. doi:10.1136/ bmjopen-2017-020991

- Prepublication history and additional material for this paper are available online. To view these files, please visit the journal online (http://dx.doi. org/10.1136/bmjopen-2017020991).

\section{WW, WC, YL and RACS} contributed equally.

Received 7 December 2017 Revised 15 January 2018 Accepted 17 January 2018

Check for updates

${ }^{1}$ Chinese Evidence-based Medicine Center and CREAT Group, State Key Laboratory of Biotherapy, West China Hospital, Sichuan University and Collaborative Innovation Centre, Sichuan, China

${ }^{2}$ Department of Health Research Methods, Evidence, and Impact (HEI), McMaster University, Hamilton, Ontario, Canada ${ }^{3}$ Department of Medicine, University of Toronto, Toronto, Ontario, Canada

${ }^{4}$ Institute of Health Policy, Management and Evaluation, University of Toronto, Toronto, Ontario, Canada

Correspondence to

Dr Xin Sun;

sunx79@hotmail.com

\section{ABSTRACT}

Objective To assess the impact of adjunctive antibiotic therapy on uncomplicated skin abscesses.

Design Systematic review and network meta-analysis. Data sources Medline, Embase, the Cochrane Central Register of Controlled Trials and ClinicalTrials.gov. Study selection A BMJ Rapid Recommendation panel provided input on design, important outcomes and the interpretation of the results. Eligible randomised controlled trials (RCTs) included a comparison of antibiotics against no antibiotics or a comparison of different antibiotics in patients with uncomplicated skin abscesses, and reported outcomes prespecified by the linked guideline panel.

Review methods Reviewers independently screened abstracts and full texts for eligibility, assessed risk of bias and extracted data. We performed random-effects metaanalyses that compared antibiotics with no antibiotics, along with a limited number of prespecified subgroup hypotheses. We also performed network meta-analysis with a Bayesian framework to compare effects of different antibiotics. Quality of evidence was assessed with The Grading of Recommendations Assessment, Development and Evaluation (GRADE) approach.

Results Fourteen RCTs including 4198 patients proved eligible. Compared with no antibiotics, antibiotics probably lower the risk of treatment failure $(\mathrm{OR} 0.58,95 \% \mathrm{Cl} 0.37$ to 0.90 ; low quality), recurrence within 1 month (OR 0.48 , $95 \% \mathrm{Cl} 0.30$ to 0.77 ; moderate quality), hospitalisation (OR $0.55,95 \% \mathrm{Cl} 0.32$ to 0.94 ; moderate quality) and late recurrence (OR $0.64,95 \% \mathrm{Cl} 0.48$ to 0.85 ; moderate quality). However, relative to no use, antibiotics probably increase the risk of gastrointestinal side effects (trimethoprim and sulfamethoxazole (TMP-SMX): OR 1.28, 95\% Cl 1.04 to 1.58; moderate quality; clindamycin: $\mathrm{OR} 2.29,95 \% \mathrm{Cl} 1.35$ to 3.88 ; high quality) and diarrhoea (clindamycin: OR 2.71, 95\% Cl 1.50 to 4.89; high quality). Cephalosporins did not reduce the risk of treatment failure compared with placebo (moderate quality). Conclusions In patients with uncomplicated skin abscesses, moderate-to-high quality evidence suggests TMP-SMX or clindamycin confer a modest benefit for several important outcomes, but this is offset by a similar risk of adverse effects. Clindamycin has a substantially higher risk of diarrhoea than TMP-SMX. Cephalosporins are probably not effective.

\section{INTRODUCTION}

Skin and soft tissue infections (SSTIs) are common, accounting for approximately five

\section{Strengths and limitations of this study}

- This review is linked to a BMJ Rapid Recommendations project, which aims to make rapid and trustworthy recommendations regarding new research that might change clinical practice.

- We systematically identified and rigorously collected the available evidence to inform choice of antibiotics for uncomplicated skin abscesses. We used the GRADE approach to assess the quality of evidence of estimates derived from pairwise and network meta-analysis.

- Sufficient data were available only for treatment failure and recurrence within 1 month, but not for other outcomes. In addition, limited data about rare adverse events were available in the randomised controlled trials (RCTs).

- Most of included RCTs involved patients treated in an emergency department, limited evidence apply to patients who present to general practice.

- Methicillin-resistant Staphylococcus aureus resistance patterns may differ across sites, individual patient clinical factors, values and preferences are variable as well. The decision whether or not to use antibiotics should take into account these importance factors.

physician visits per year for every 100 people, for which abscess/cellulitis is most common. ${ }^{1}$ Hospital admissions for SSTIs appear to be increasingly common ${ }^{2}$ possibly because of the high prevalence of community-associated methicillin-resistant Staphylococcus aureus (CA-MRSA). ${ }^{3}$ In the USA, approximately $59 \%$ of patients with SSTIs were infected with CA-MRSA, ${ }^{3}{ }^{4}$ and CA-MRSA infections has become a global problem.

The appropriate strategies for managing SSTIs, especially those caused by CA-MRSA, are yet to be established. Until now, the role of adjuvant antibiotic therapy in addition to incision and drainage (I\&D) has been controversial, ${ }^{5-7}$ at least in part because randomised controlled trials (RCTs) have failed to consistently show benefit. A systematic review 
Box 1 Linked articles in this BMJ Rapid Recommendation cluster.

- Vermandere M, Aertgeerts B, Agoritsas T, et al. Antibiotics after incision and drainage for uncomplicated skin abscesses: a clinical practice guideline. BMJ 2018;360:k243

Summary of the results from the Rapid Recommendation process

- Wang W, Chen W, Liu Y, et al. Antibiotics for uncomplicated skin abscesses: systematic review and network meta-analysis. BMJ Open 2018;8:e020991

- Review of all available randomised trials that assessed antibiotics for uncomplicated skin abscesses

- MAGICapp (http://magicapp.org/goto/guideline/jIRvQn/section/ER5RAn) Expanded version of the results with multilayered recommendations, evidence summaries, and decision aids for use on all devices.

including 5 RCTs with 687 patients and 7 observational studies with 1336 patients concluded that adjuvant antibiotics may not improve the chance of cure beyond the benefits of I\&D alone. ${ }^{8}$ Recently, two large RCTs were published, ${ }^{910}$ both of which suggested that adjunctive trimethoprim and sulfamethoxazole (TMP-SMX) or clindamycin may improve cure rate compared with placebo.

Prompted by the BMJ Rapid Recommendation team's suggestions that this new evidence might change clinical practice, we conducted this systematic review to inform a BMJ Rapid Recommendation-a project that aims to make rapid and trustworthy recommendations regarding new research that might change clinical practice. ${ }^{11} \mathrm{We}$ addressed two clinical questions-in patients with uncomplicated skin abscesses, what is the impact of antibiotic plus I\&D compared with I\&D alone; and what are the impacts of the different antibiotic options.

\section{METHODS}

We followed the reporting standards set by Preferred Reporting Items for Systematic reviews and Meta-Analyses (PRISMA) ${ }^{12}$ and the PRISMA network meta-analysis extension statement. ${ }^{13}$

\section{Relationship to the BMJ Rapid Recommendation panel}

According to the BMJ Rapid Recommendations process, ${ }^{11}$ a semi-independent guideline panel provided critical oversight to the review and identified populations, subgroups and outcomes of interest. The panel included three people with lived experience of skin abscesses, physicians (five general practitioners, two paediatricians, three infectious diseases specialists, a dermatologist and four general internists) and several research methodologists. The panel members helped interpret the evidence in this review and make clinical practice recommendations. ${ }^{14}$

\section{Patient involvement}

Two adult patients and one parent of a child patient were full panel members of the linked BMJ Rapid Recommendation. ${ }^{11}$ They worked with the rest of the panel, with the help of a patient liaison expert, to identify the outcomes that were important for decision-making; they also led the interpretation of the results based on what they expected the typical patient values and preferences to be, as well as the variation between patients.

\section{Eligibility criteria}

We included RCTs that included a comparison of antibiotics versus no antibiotics or a comparison of different types of antibiotics in children or adult patients with uncomplicated skin abscesses, and explicitly reported data on at least one of the outcomes prespecified by the BMJ Rapid Recommendation guideline panel. Furuncles (boils) and carbuncles were included in the definition of skin abscesses, while pustules and papules were not. No restrictions were applied to types of antibiotics. The prespecified outcomes included treatment failure, recurrence (at same or different site), hospitalisation, need for an additional surgical procedure, a similar infection in a household member, pain, invasive infections, gastrointestinal side effects, diarrhoea, nausea, death and anaphylaxis.

\section{Literature search}

We searched Medline, EMBASE and the Cochrane Central Register of Controlled Trials (CENTRAL) from inception to 17 August 2017 to identify relevant studies, without language restrictions. We combined database-specific subject headings (such as MeSH terms) and free-text terms regarding 'skin abscess' and 'anti-infective agents' to search for potentially eligible studies. We also searched ClinicalTrials.gov to identify any unpublished studies and reviewed the reference lists of the included RCTs. Online supplementary appendix 1 presents the full search strategy.

\section{Study process}

Three reviewers (WW, WC and YL), independently and in duplicate, screened titles/abstracts for potential eligibility and full texts for final eligibility; assessed risk of bias and collected data from each eligible trial using standardised, pilot tested forms. Reviewers resolved disagreement through discussion or by adjudication by a third reviewer (LL).

\section{Risk of bias assessment}

We assessed risk of bias of RCTs using a modified version of the Cochrane tool, in which we used response options of 'definitely or probably yes' (assigned a low risk of bias) and 'definitely or probably no' (assigned a high risk of bias), an approach that has been validated. ${ }^{15-17}$ The items for the risk of bias tool included random sequence generation; concealment of treatment allocation; blinding of participants, caregivers and outcome assessors; infrequent missing outcome data.

\section{Data extraction}

We collected the following information from each eligible RCT: study characteristics (study design, total 


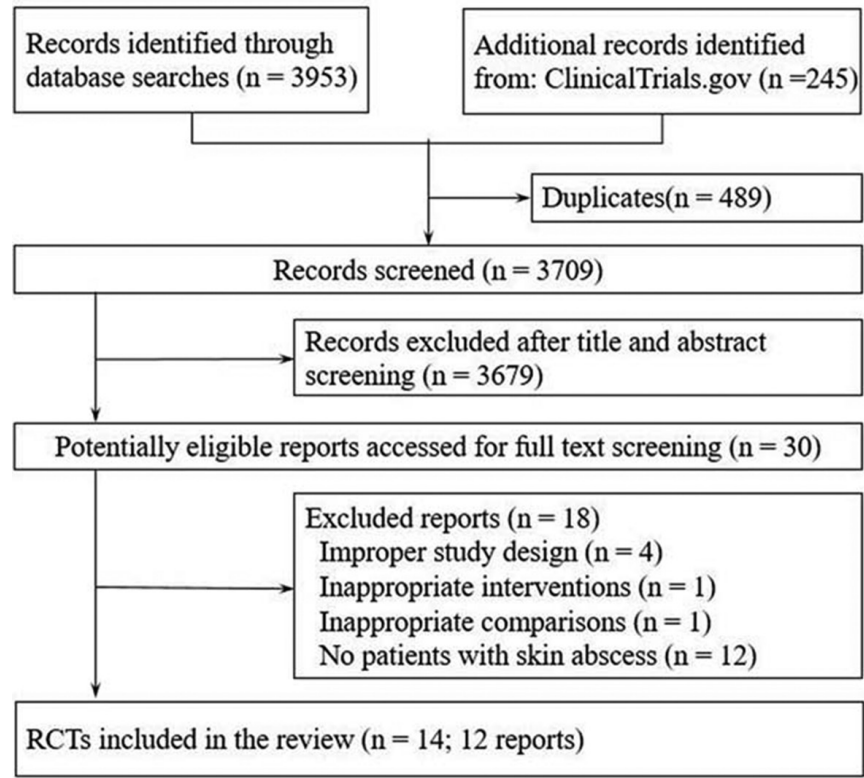

Figure 1 Flow chart of selection of studies.

number of patients, length of follow-up, whether the trial was an international study, number of sites and stratification by skin abscess if a trial included other populations with infection); patient characteristics (gender, age and infection pathogen, type of abscess and inclusion criterion); intervention characteristics (surgical treatment for abscess, type of antibiotics used in the treatment group, agents used in control, dose and duration of treatment) and outcome data (outcomes of interest, events and numbers of patients included for analyses in each group).

\section{Data analysis and rating quality of evidence}

For our primary comparison of antibiotics versus no antibiotics, we conducted pairwise meta-analyses. We used the random-effects Mantel-Haenszel (M-H) method to estimate ORs and $95 \%$ CIs. For the outcomes with low event rate $(<5 \%)$, we pooled data using Peto's method. We examined statistical heterogeneity among studies using the $\mathrm{I}^{2}$ statistic and Cochran's $\mathrm{X}^{2}$ test. We used complete case analysis for efficacy outcomes and as-treated analysis for safety outcomes as our primary analyses.

We planned, according to the guideline panel's specification, five hypotheses to explain variability in effect estimates between studies: antibiotic MRSA coverage (hypothesising larger effects with MRSA coverage vs no MRSA coverage), individual antibiotics (hypothesising smaller effects with TMP-SMX vs clindamycin), type of patients (hypothesising larger effects with children vs adults), treatment course (hypothesising smaller effects with $<7$ days vs $\geq 7$ days) and abscess size (hypothesising larger effects with $\geq 5 \mathrm{vs}<5 \mathrm{~cm}$ ). We conducted subgroup analyses if there were at least two trials in each subgroup category.

We conducted the following sensitivity analyses to examine the robustness of effect estimates: analyses using alternative effect measures (OR vs relative risk), statistical models (fixed vs random effects), pooling methods (Peto vs M-H), alternative methods for random-effects meta-analysis (DerSimonian and Laird (DL) vs HartungKnapp-Sidik-Jonkman (HKSJ)) and alternative assumptions about missing data; as well as analyses omitting trials published before 1990 and trials with patients treated by primary suture rather than open drainage and, for treatment failure, excluding trials that considered recurrences as treatment failure.

We also conducted a network meta-analysis (NMA) of RCTs using a Bayesian approach to compare effects of alternative antibiotics. We fitted a Bayesian random-effect hierarchical model with non-informative priors and adjusted for correlation between effects in multiarm trials. We assumed common heterogeneity within the network. We generated posterior samples using Markov Chain Monte-Carlo simulation technique running the analysis in three parallel chains. We used 10000 burn-in simulations to allow convergence and then a further 100000 simulations to produce the outputs. We assessed model convergence using Gelman and Rubin diagnostic test. ${ }^{18}$ The primary network meta-analysis was conducted with uninformative priors with a uniform distribution, Unif $(0,5)$. We also conducted a sensitivity analysis with weakly informative priors $(\mathrm{HN}(0,1) \mathrm{I}(0$,$) .$

We report pooled ORs for direct, indirect and mixed network meta-analysis estimates and associated 95\% credible intervals. We present the direct, indirect and network effect estimates. We used the node-splitting approach for the assessment of loop inconsistency in our triangular loop. ${ }^{19}$ Finally, we presented pooled risk differences (RD) for all the comparisons. To estimate absolute effect for treatment failure, we used the median baseline risk from the no antibiotics arms and applied it to the relative effect from the network estimates. We performed all analyses with R (R Core Team, 2016, Vienna, Austria: $\mathrm{R}$ Foundation for Statistical Computing) using the gemtc library. ${ }^{20}$

We followed the GRADE approach to rate the quality of evidence of estimates derived from pairwise and network meta-analysis. ${ }^{21} 22$ Direct evidence from RCTs starts at high quality and can be rated down based on risk of bias, indirectness, imprecision, inconsistency and publication bias. When the estimates were not robust to the worst plausible analysis, we rated down our certainty in the evidence for risk of bias. ${ }^{23}$ For NMA estimates, we rated the quality of evidence in each of the direct, indirect and NMA estimates. ${ }^{22}$ The rating of indirect estimates starts at the lowest rating of the two pairwise estimates that contribute as first-order loops to the indirect estimate but can be rated down further for intransitivity. If direct and indirect estimates contributed similar power to the network estimate, then we used the higher rating. The network estimates were further rated down if they were incoherent. 


\section{RESULTS}

Our search yielded 4198 potentially relevant reports and $12^{91024-33}$ ultimately proved eligible (figure 1). One report $^{29}$ included two independent RCTs, and the other ${ }^{28}$ reported results of a factorial trial that also compared two surgical approaches and reported results separately for each approach. In total, there were 14 RCTs that enrolled 3541 patients with uncomplicated skin abscesses (range 14-1265), of which 9 were multicentre studies, ${ }^{9} 102629-33$ and 5 were published prior to the year of 2000. ${ }^{25283133}$ Eleven trails reported study setting, of which nine 10 24-26 $283032(n=3068)$ were conducted in emergency department, one ${ }^{33}(n=174)$ in outpatient dermatology clinics and the other one ${ }^{27}$ in an Integrated Soft Tissue Infection Services clinic involving patients with high rates of comorbidity, such as infection with hepatitis C, hepatitis B or HIV.

Two trials ${ }^{2526}$ exclusively enrolled adults, two exclusively enrolled children, ${ }^{2431}$ seven included both adults and children $^{9} 1029303233$ and three others provided no details. ${ }^{27} 28$ Three trials reported abscess size of enrolled patients. ${ }^{9} 1032$ The largest trial ${ }^{10}$ specifically focused on small abscesses, in which no patients had signs of systemic infection. Two trials ${ }^{1027}$ included a proportion of patients with diabetes $(2.4 \%-11 \%)$ and seven trials ${ }^{94-2629} 32$ excluded patients with diabetes. The most common pathogen cultured was MRSA, the proportion of which ranged from $43.5 \%$ to $87.8 \%$. The resistance rates of clindamycin ${ }^{924} 32$ ranged from $7.1 \%$ to $18 \%$, while TMP-SMX 10242632 ranged from $0 \%$ to $2.6 \%$. Ten trials reported surgical treatment for abscess, of which nine performed incision and drainage 9 $1024-283032^{2}$ and the other performed incision, curettage and primary suture ${ }^{28}$ (table 1 ). The descriptions of abscess definitions were summarised in table A of online supplementary appendix 2.

Antibiotics included TMP-SMX, clindamycin, early cephalosporins, late cephalosporins and azithromycin. Eight trials ${ }^{9} 10$ 24-28 compared antibiotics (TMP-SMX, clindamycin, cephradine, cephalexin) with no antibiotics, of which six administered antibiotics for at least 7 days $^{91024-27}$; the two others used clindamycin for 4 days. ${ }^{28}$ Six other trials ${ }^{29-33}$ examined comparative effects of alternative antibiotics, and the treatment courses ranged from 3 to 14 days. The length of follow-up ranged from 7 to 90 days across the trials (table 1 ).

All the 14 trials adequately generated their randomisation sequence, $11(78.6 \%)$ concealed treatment allocation, $10(71.4 \%)$ blinded participants, $11(78.6 \%)$ blinded caregivers, $11(78.6 \%)$ blinded outcome assessors and 6 $(42.8 \%)$ trials had infrequent missing outcome (see table $\mathrm{B}$ in online supplementary appendix 2).

\section{Effects of antibiotics versus no antibiotics}

Eight trials ${ }^{9} 10$ 24-28 compared antibiotics with no antibiotics. The risk of treatment failure was probably lower in patients randomised to antibiotics (eight trials, ${ }^{9} 10$ 24-28 OR $0.58,95 \%$ CI 0.37 to $0.90, \mathrm{I}^{2}=48 \%$; risk difference 37 fewer (56 fewer to 9 fewer) per 1000 patients with uncomplicated skin abscess; low quality; figure 2 and table 2). For this outcome, we found sufficient information to conduct three prespecified subgroup analyses: analysis by age $(\geq 18 \mathrm{vs}<18$ years $)$ and individual antibiotics (TMP-SMX vs clindamycin) suggested no significant difference (interaction $\mathrm{P}=0.36$ and 0.95 , figures 3 and 4). Antibiotics with activity against MRSA (TMPSMX and clindamycin) proved more likely to reduce the risk of treatment failure than those without activity against MRSA (first-generation cephalosporins) (interaction $\mathrm{P}=0.008$; figure 5; antibiotics with MRSA activity, six trials, ${ }^{910242628}$ OR $0.45,95 \%$ CI 0.33 to $0.62, \mathrm{I}^{2}=13 \%$; high quality; antibiotics without MRSA activity (cephalosporins), two trials, ${ }^{2527}$ OR $1.82,95 \%$ CI 0.68 to $4.85, \mathrm{I}^{2}=0 \%$; moderate quality).

Patients receiving antibiotics probably had lower risk of recurrence both within 1 month (six trials, ${ }^{9} 10242628$ OR $0.48,95 \%$ CI 0.30 to $0.77, \mathrm{I}^{2}=45 \%$; 63 fewer ( 86 fewer to 27 fewer) per 1000 patients; moderate quality; figure 2 and table 2), and at extended follow-up, from 1 to 3 months (two trials, ${ }^{1024}$ OR $0.64,95 \%$ CI 0.48 to $0.85, \mathrm{I}^{2}=0 \% ; 78$ fewer (118 fewer to 31 fewer) per 1000 patients; moderate quality; figure 2 and table 2). A subgroup by individual antibiotics (TMP-SMX vs clindamycin) suggested that there was no difference between clindamycin and TMP-SMX (interaction $\mathrm{P}=0.71$, figure 6).

Hospitalisation was probably less common in patients randomised to antibiotics (two trials, ${ }^{1024}$ OR $0.55,95 \%$ CI 0.32 to $0.94, \mathrm{I}^{2}=0 \%$; 17 fewer ( 26 fewer to 2 fewer) per 1000 patients; moderate quality; table 2).

Only one RCT $(n=1057)^{10}$ reported pain, additional surgical procedures, infection in a household member, invasive infections (table 2 ). Antibiotics probably reduced pain at 3 or 4 days (OR $0.76,95 \%$ CI 0.60 to $0.97 ; 68$ fewer (126 fewer to 8 fewer) per 1000 patients; moderate quality) and 8-10 days of follow-up (OR 0.56, 95\% CI 0.35 to 0.88 ; 42 fewer ( 63 fewer to 11 fewer) per 1000 patients; moderate quality), as well as additional surgical procedures at 49-63 days of follow-up (OR 0.58, 95\% CI 0.39 to 0.87 ; 52 fewer ( 78 fewer to 16 fewer) per 1000 patients; moderate quality). The risk of infection in a household member was probably lower with antibiotics, but the CI included no effect (OR $0.58,95 \%$ CI 0.34 to 1.01 ; moderate quality). Antibiotics probably did not appear to lower the risk of invasive infections at 7-14 days (OR 1.02, $95 \%$ CI 0.14 to 7.24 ; moderate quality), at 42 and 56 days (OR 7.46, 95\% CI 0.15 to 376.12; moderate quality).

The incidence and severity of adverse events is likely to differ between antibiotics, thus we analysed the safety outcomes separately for each antibiotic (clindamycin and TMP-SMX). Both TMP-SMX (four trials, ${ }^{9} 102426$ OR $1.28,95 \%$ CI 1.04 to $1.58, \mathrm{I}^{2}=0 \% ; 21$ more ( 3 more to 43 more) per 1000 patients; moderate quality) and clindamycin (one trial, ${ }^{9}$ OR 2.29, $95 \%$ CI 1.35 to 3.88 ; 95 more (28 more to 187 more) per 1000 patients; moderate quality) were associated with increased risk of overall gastrointestinal side effects. Clindamycin increases the risk of diarrhoea (one trial, ${ }^{9}$ OR $2.71,95 \%$ CI 1.50 to 


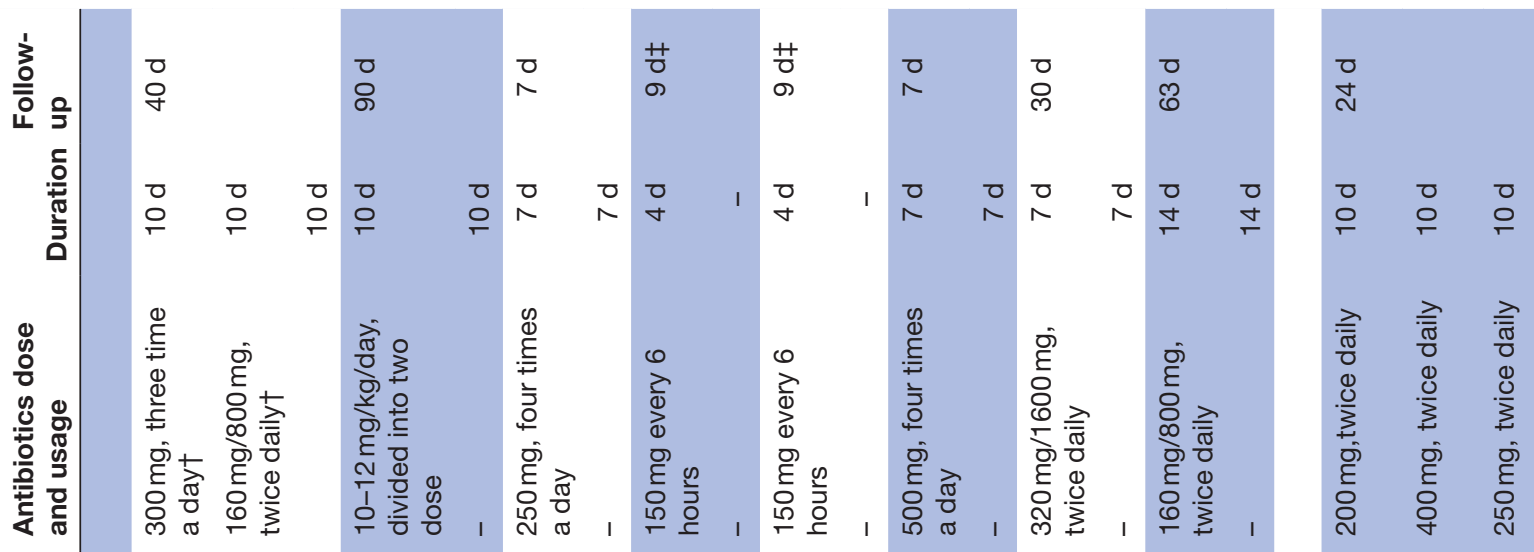

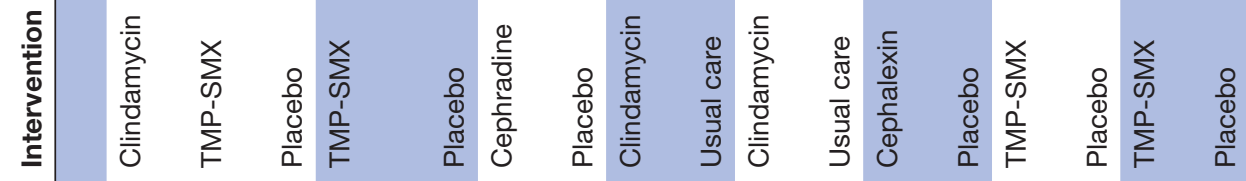

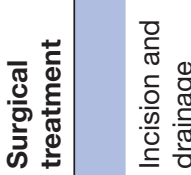

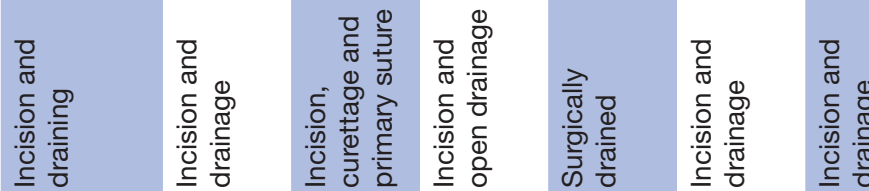

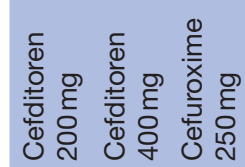

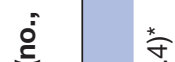

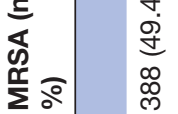

ซ. สุ่

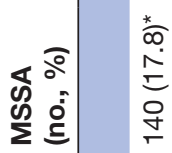

$i$
$\infty$
$\infty$$\quad \frac{0}{\infty}$

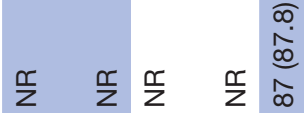

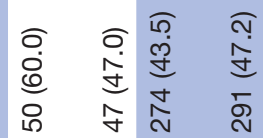

$\frac{n}{z}$

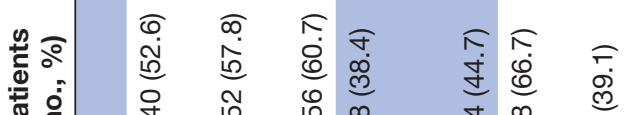

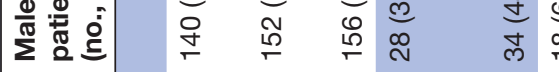

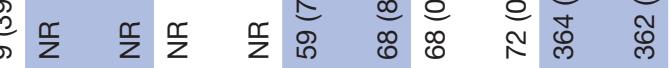

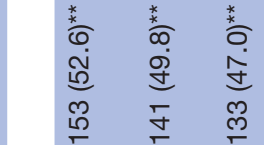
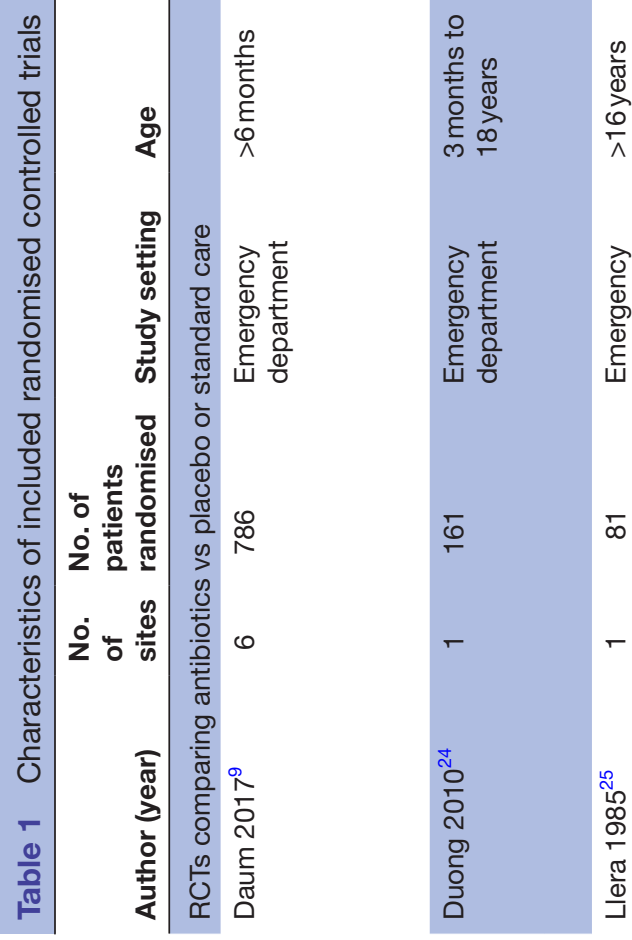

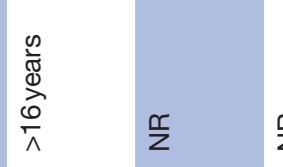

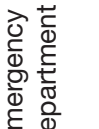

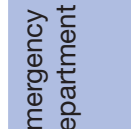

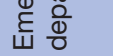

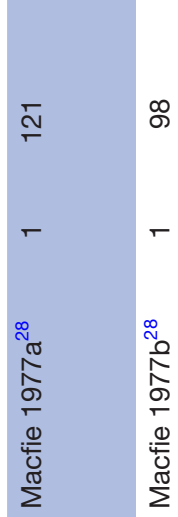

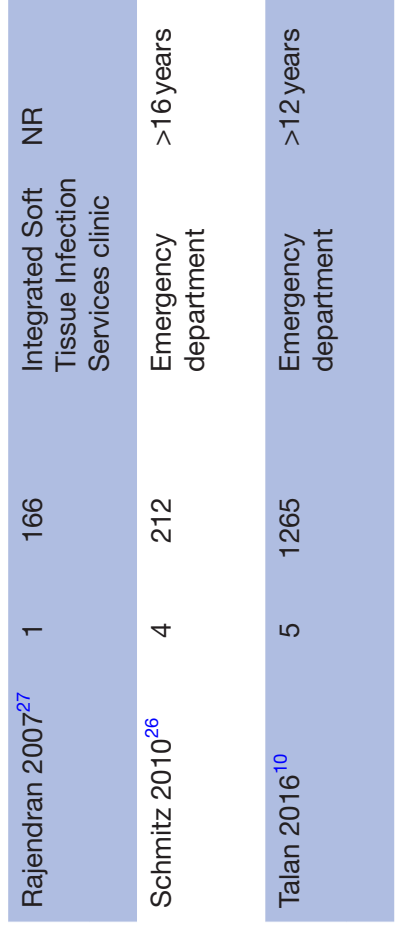

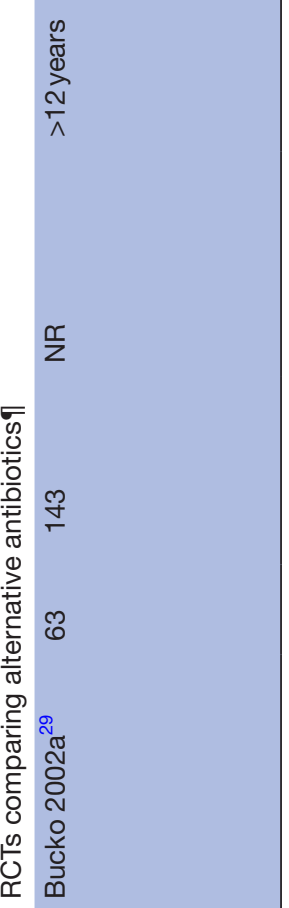




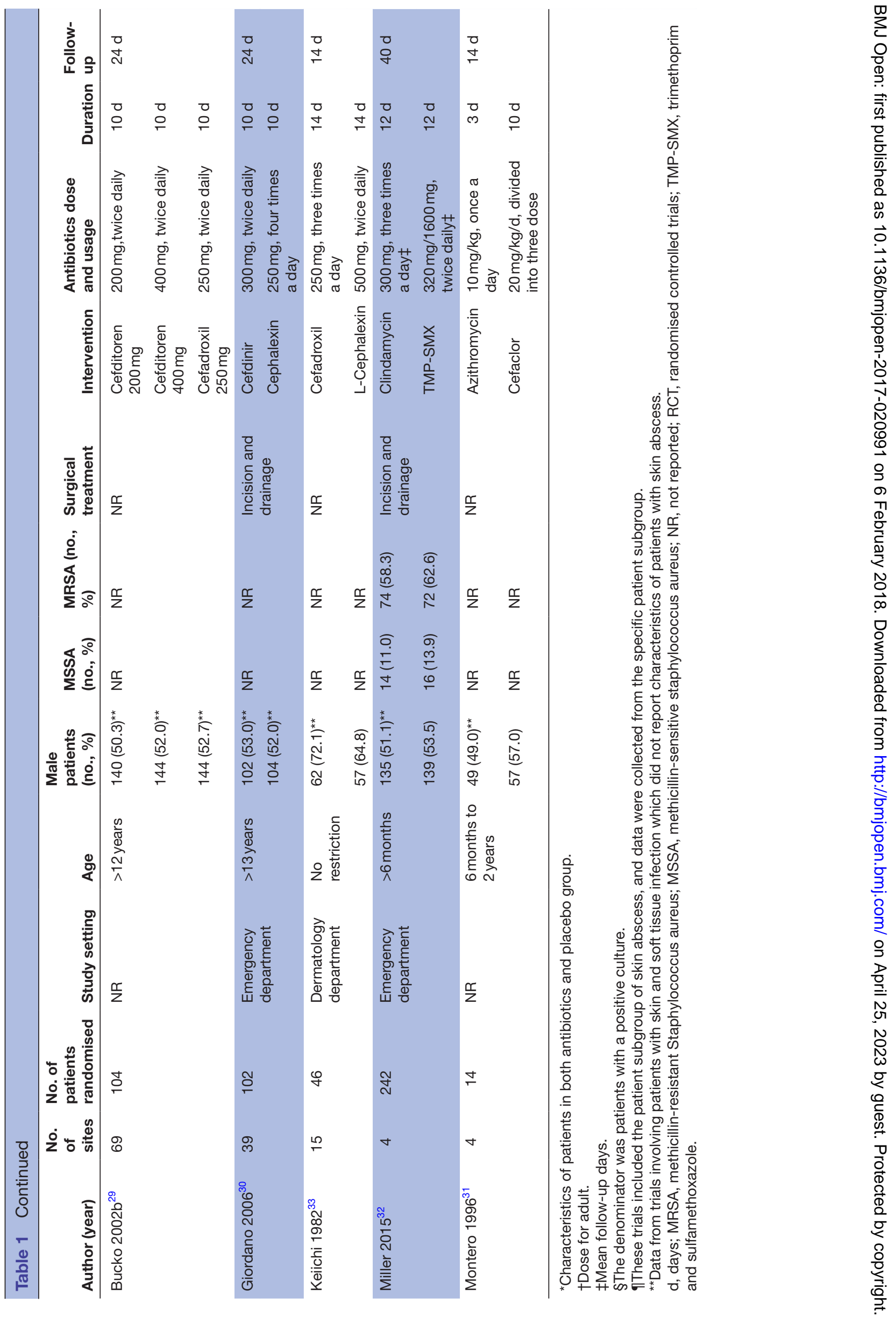




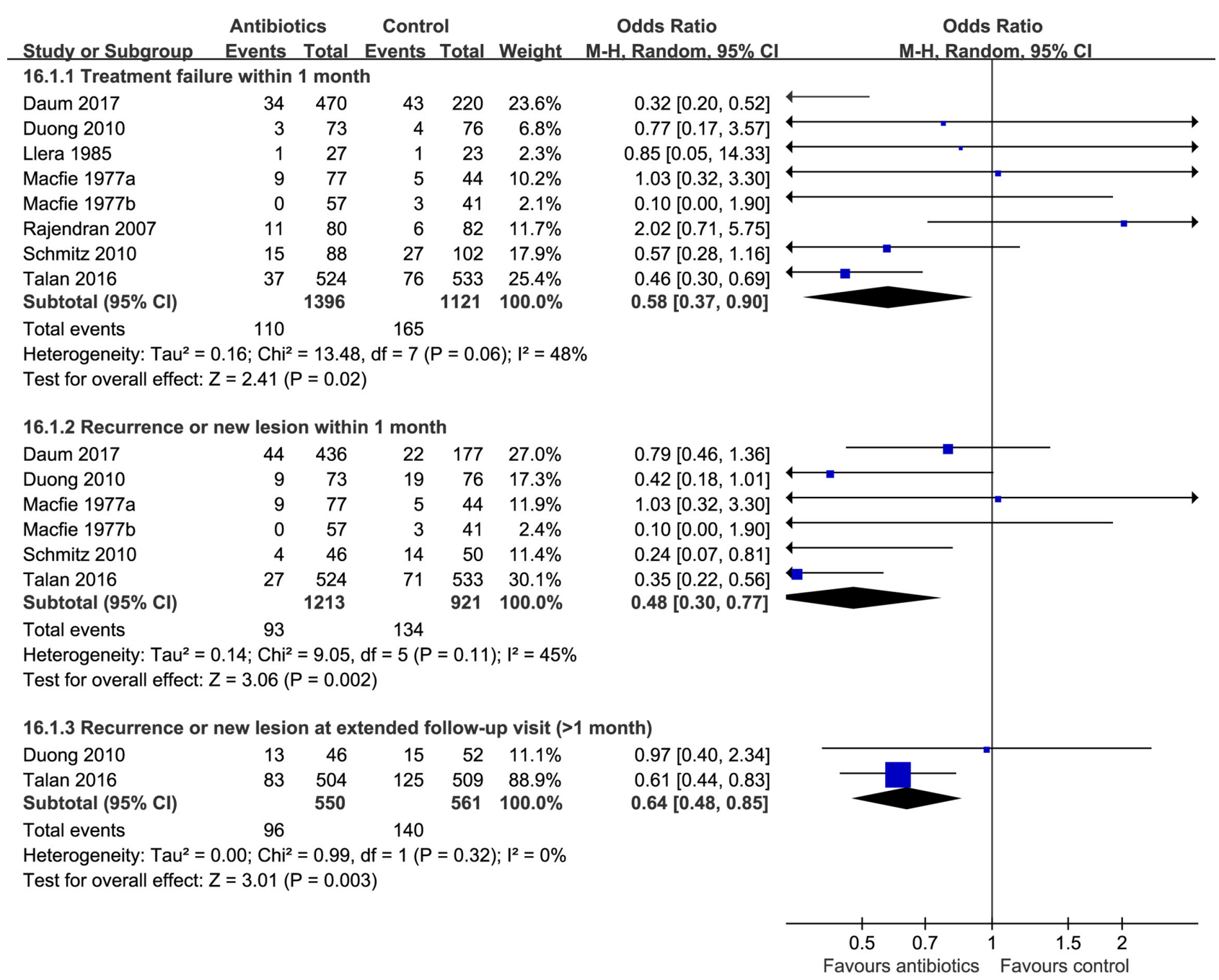

Figure 2 Effects of antibiotics vs no antibiotics on treatment failure and recurrence.

4.89; 96 more (30 more to 193 more) per 1000 patients; high quality), while TMP-SMX probably does not (three trials, ${ }^{9} 1026$ OR $0.92,95 \%$ CI 0.70 to $1.22, \mathrm{I}^{2}=0 \%$; moderate quality) (table 3$)$. Two large trials ${ }^{910}(\mathrm{n}=2051)$ monitored for Clostridium difficile infection (CDI) with routine clinical monitoring: no $\mathrm{CDI}$ occurred in any treatment arm. TMP-SMX probably increases the risk of nausea (TMP-SMX OR $1.49,95 \%$ CI 0.98 to 2.25 , $\mathrm{I}^{2}=11 \%$; moderate quality), while clindamycin may not (OR $0.96,95 \%$ CI 0.31 to 3.02; moderate quality). TMP-SMX does not appear to have an important effect on the risk of sepsis (one trial, ${ }^{10}$ OR $7.24,95 \%$ CI 0.14 to 364.86 ; moderate quality) or death (two trials, ${ }^{910}$ OR $0.98,95 \%$ CI 0.06 to 15.68 ; no difference ( 4 fewer to 4 more) per 1000; high quality) because both outcomes were so rare. The risk of anaphylaxis is uncertain (TMPSMX OR 2.32, 95\% CI 0.67 to 8.06; clindamycin OR $2.17,95 \%$ CI 0.62 to 7.58 ; low quality, table 3 and table $\mathrm{C}$ in online supplementary appendix 2 ).

\section{Subgroup analyses and sensitivity analyses}

There was only enough information to conduct prespecified subgroup analyses for the treatment failure and recurrence outcomes (see above). Sensitivity analyses using alternative pooling methods, effect measures and statistical models did not result in a change in interpretation (tables A-D in online supplementary appendix 3). The CIs for abscess treatment failure, late recurrence, hospitalisation, gastrointestinal side effects and nausea excluded no effect with the DL method but not the HKSJ method (tables E in online supplementary appendix 3). For the results of the primary analysis suggested statistically significant treatment effect, sensitivity analyses using plausible assumptions about missing data were not robust to the worst plausible analysis (table F in online supplementary appendix 3).

The results and interpretation of the network meta-analysis did not change when we used weakly informative priors instead of than uninformative priors (data not shown).

\section{Comparative effects of alternative antibiotics}

Of the 14 trials, ${ }^{9} 28-3032$ included direct comparison between different types of antibiotics.

Comparative effects on treatment failure

There was sufficient information to conduct an NMA for treatment failure only. The NMA included 12 trials, 
Table 2 Summary of GRADE evidence profile of antibiotics vs placebo or standard care

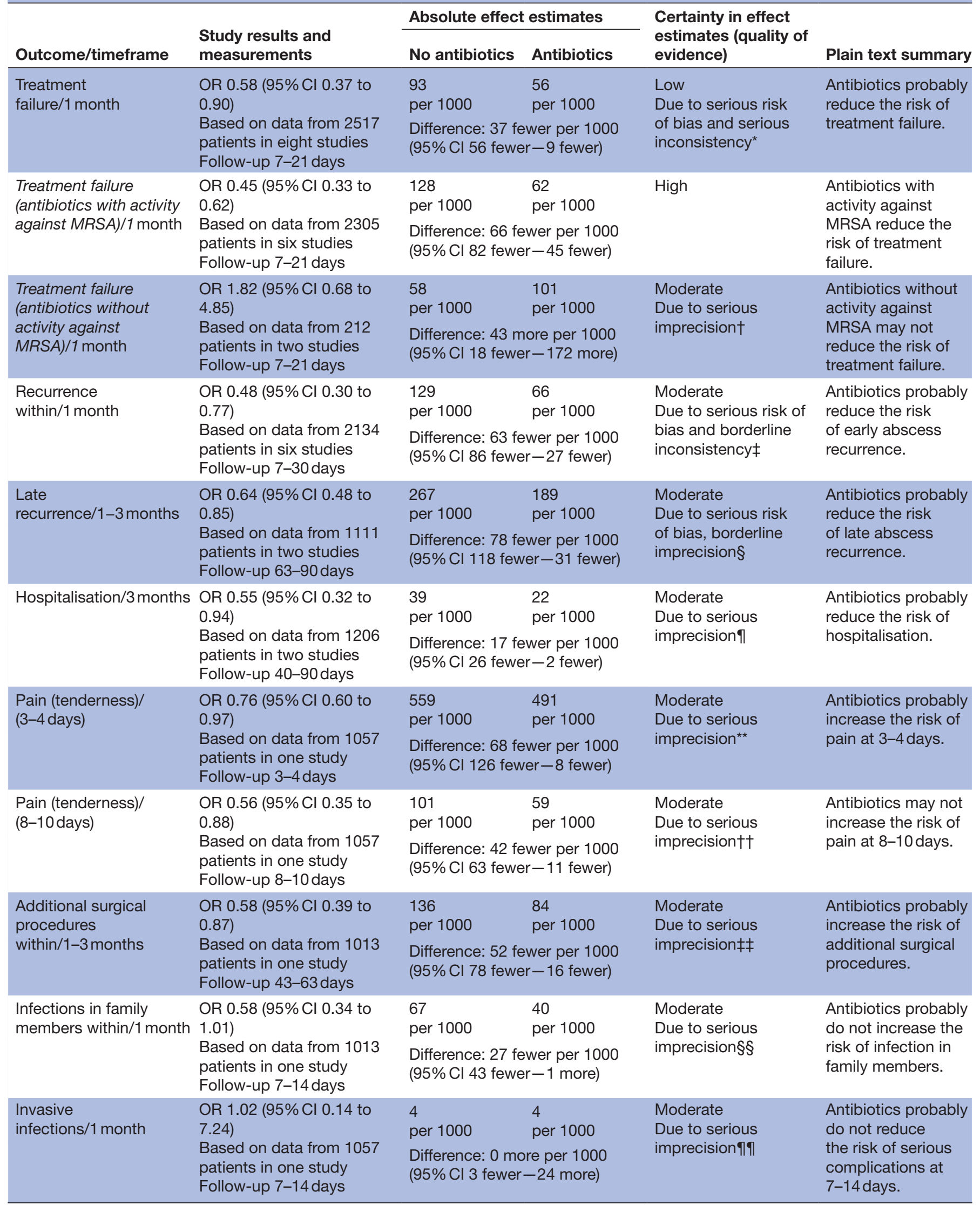

Continued 
Table 2 Continued

\begin{tabular}{|c|c|c|c|c|c|}
\hline \multirow[b]{2}{*}{ Outcome/timeframe } & \multirow{2}{*}{$\begin{array}{l}\text { Study results and } \\
\text { measurements }\end{array}$} & \multicolumn{2}{|c|}{ Absolute effect estimates } & \multirow{2}{*}{$\begin{array}{l}\text { Certainty in effect } \\
\text { estimates (quality of } \\
\text { evidence) }\end{array}$} & \multirow[b]{2}{*}{ Plain text summary } \\
\hline & & No antibiotics & Antibiotics & & \\
\hline $\begin{array}{l}\text { Invasive } \\
\text { infections/3 months }\end{array}$ & $\begin{array}{l}\text { OR } 7.46 \text { (95\% Cl } 0.15 \text { to } \\
376.12) \\
\text { Based on data from } 1013 \\
\text { patients in one study } \\
\text { Follow-up 42-56 days }\end{array}$ & $\begin{array}{l}0 \\
\text { per } 1000 \\
\text { Difference: } 2 \mathrm{~m} \\
(95 \% \mathrm{Cl} 4 \text { fewe }\end{array}$ & $\begin{array}{l}1 \\
\text { per } 1000 \\
\text { re per } 1000 \\
-8 \text { more) }\end{array}$ & $\begin{array}{l}\text { Moderate } \\
\text { Due to serious } \\
\text { imprecision }^{\star \star \star}\end{array}$ & $\begin{array}{l}\text { Antibiotics probably } \\
\text { do not reduce } \\
\text { the risk of serious } \\
\text { complications at } \\
42-56 \text { days. }\end{array}$ \\
\hline
\end{tabular}

Evidence have summarised at Magic App (www.magicapp.org/public/guideline/jIRvQn).

${ }^{*}$ Risk of bias: serious. There was substantial missing data/lost to follow-up: the results are not robust to worth plausible sensitivity analysis (assuming that missing patients from the control arms have the same rate of treatment failure as those with complete followup, and five times the rate of treatment failure in the patients who were lost to follow-up in the antibiotic arm); inconsistency: serious. Effects might differ in different type of antibiotics.

†Imprecision: serious. $\mathrm{Cl}$ approaches no effect.

¥Risk of bias: serious. There was substantial missing data/lost to follow-up: the results are not robust to worth plausible sensitivity analysis; inconsistency: no serious. The magnitude of statistical heterogeneity was high, with $\mathrm{I}^{2}=45 \%$, but the direction of effect was similar in almost all trials, favouring antibiotics over no antibiotics.

$\S$ Risk of bias: serious. Incomplete data and/or large loss to follow-up: results are not sensitive to worst plausible sensitivity analysis: OR $1.48,95 \% \mathrm{Cl} 0.55$ to 3.96 ; imprecision: no serious. A single large study, and one small study contributed data to this outcome.

IIImprecision: serious. $\mathrm{Cl}$ approaches no effect.

**Imprecision: serious. Only data from one study, $\mathrm{Cl}$ approaches no effect.

††Imprecision: serious. Only data from one study.

ł¥Imprecision: serious. Data from one study only.

$\S \S I m p r e c i s i o n:$ serious. Only data from one study; $\mathrm{Cl}$ include no effect.

ПๆImprecision: serious. Only data from one study.

***Imprecision: serious. Only data from one study; $\mathrm{Cl}$ include no effect.

GRADE, Grading of Recommendations Assessment, Development and Evaluation; MRSA, methicillin-resistant Staphylococcus aureus.

with 8 trials comparing antibiotics with no antibiotics and 5 trials that compared different antibiotics with each other (there was one three-arm RCT ${ }^{9}$; figure 7). We grouped cephalosporins into early (first and second) generation or late (third and fourth) generation cephalosporins. We excluded a single trial that compared azithromycin with early cephalosporin because there was only one event, ${ }^{31}$ and another trial in which both antibiotics were early generation cephalosporins. ${ }^{33}$

Pairwise comparisons had $\mathrm{I}^{2}$ values from $0 \%$ to $17.3 \%$ (figure 8). There was no incoherence between the direct and indirect evidence for any of the comparisons using the back-calculation (figure 8) or node-splitting approach (figure 9; table A in online supplementary appendix 4).

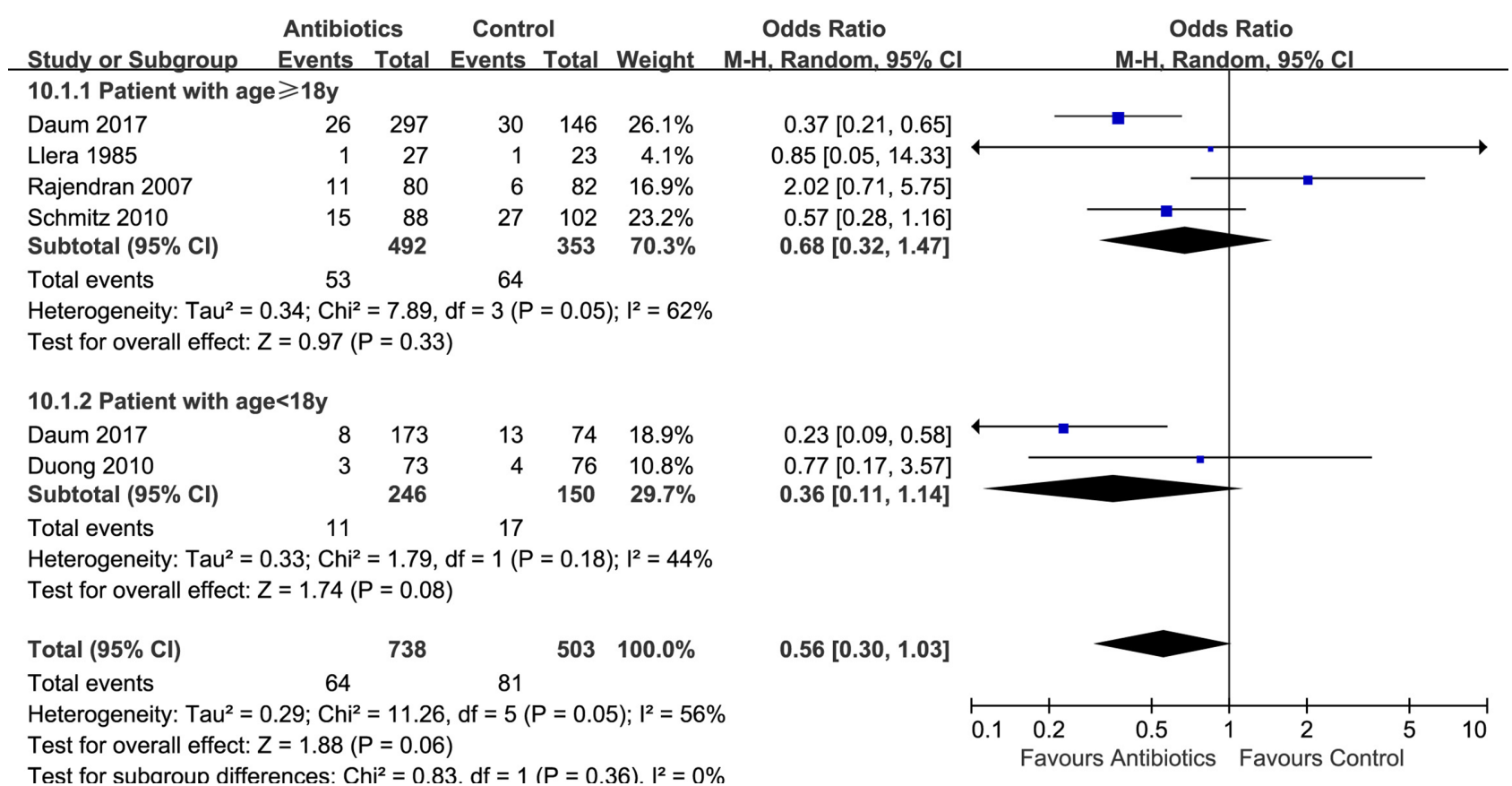

Figure 3 Subgroup analysis of treatment failure within 1 month by age ( $\geq 18 \mathrm{vs}<18$ years). 


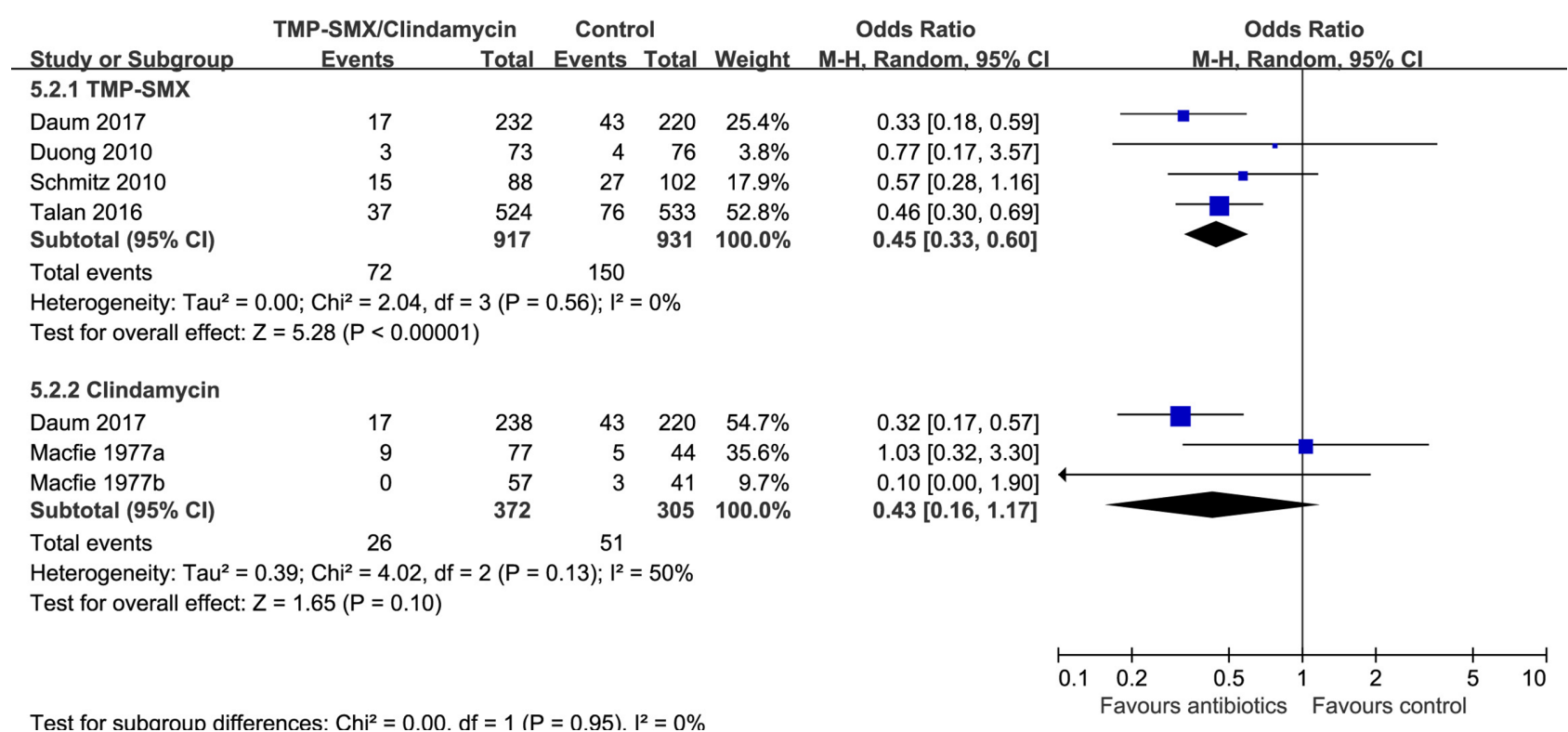

Figure 4 Subgroup analysis of treatment failure by type of antibiotics (trimethoprim and sulfamethoxazole (TMP-SMX) vs clindamycin).

TMP-SMX and clindamycin both reduce treatment failure compared with no antibiotics (NMA OR $0.61,95 \%$ CI 0.41 to 0.85 ; NMA OR $0.55,95 \%$ CI 0.33 to 0.87 , both moderate quality). There did not appear to be a difference between clindamycin and TMP-SMX (high quality; tables 4 and 5). With moderate quality, TMP-SMX and clindamycin probably confer a lower treatment failure than early generation cephalosporins (TMP-SMX NMA OR 0.42, 95\% CI 0.12 to 1.07 ; clindamycin NMA OR $0.39,95 \%$ CI 0.11 to 1.02 ; tables 6 and 7) and for late-generation cephalosporins.

\section{Comparative effects of TMP-SMX versus clindamycin on other outcomes}

A single trial ${ }^{9}$ reported recurrence, diarrhoea and nausea within 1 month. Use of TMP-SMX, compared with clindamycin, was probably associated with higher risk of abscess recurrence (OR 2.14, 95\% CI 1.11 to $4.12 ; 67$ more (7 more to 163 more) per 100 patients; low quality), but lower risk of diarrhoea (OR 0.29 , $95 \%$ CI 0.16 to 0.55 ; 109 fewer (132 fewer to 66 fewer) per 1000 patients, high quality). Nausea was rare (OR $1.90,95 \%$ CI 0.69 to 5.21 ;

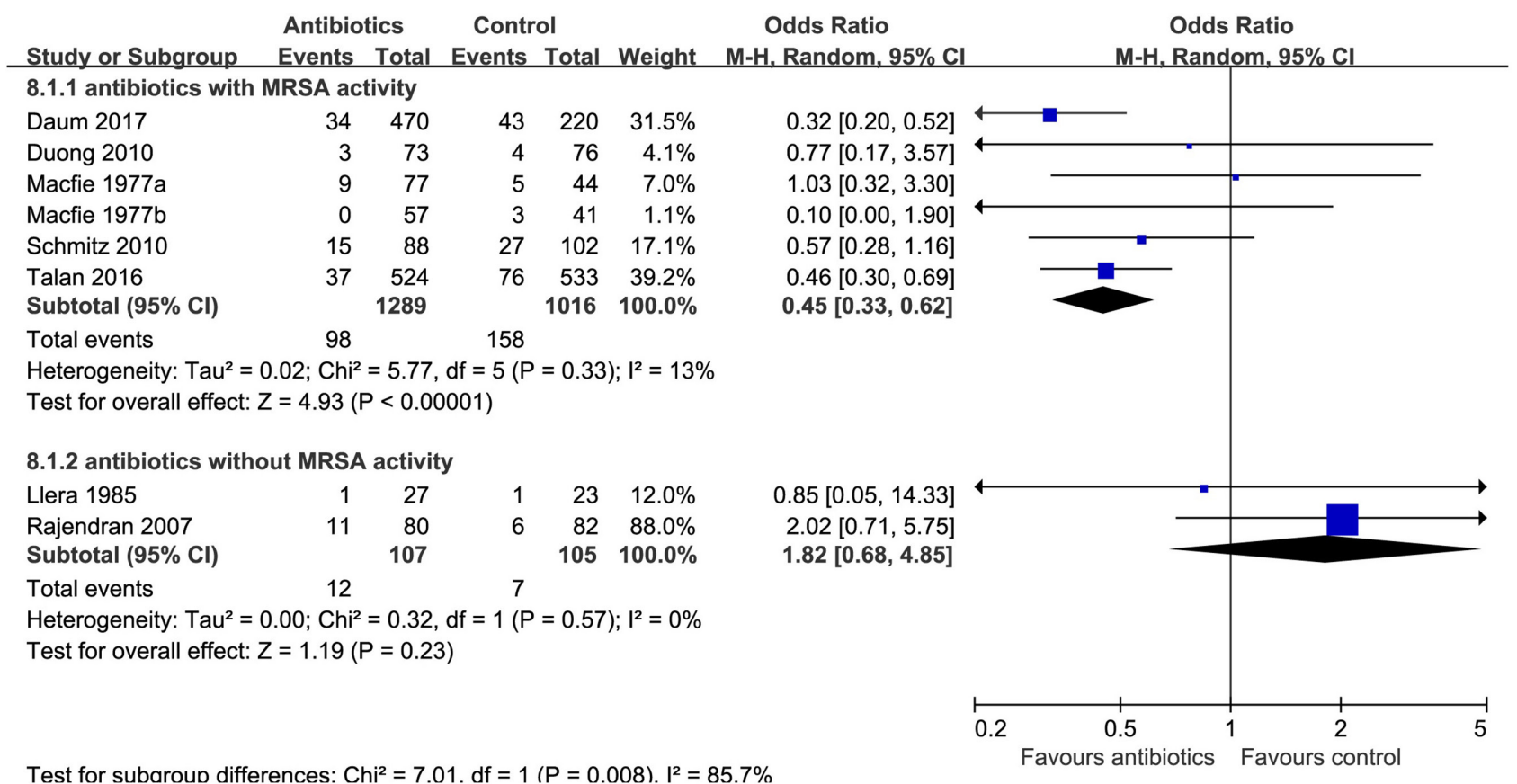

Figure 5 Subgroup analysis of treatment failure within 1 month by antibiotics with vs without methicillin-resistant Staphylococcus aureus (MRSA) activity. 
20 more ( 7 fewer to 86 more) per 1000 patients, moderate quality; table 5).

\section{Comparison between early cephalosporins}

One trial ${ }^{33}$ compared two early cephalosporins (cefadroxil vs cephalexin); and there was only one event (RD -0.04 , $95 \%$ CI -0.15 to 0.07 ).

\section{DISCUSSION}

\section{Findings and interpretations}

We found moderate-to-high quality evidence that in patients with uncomplicated skin abscesses who treated with I\&D, adjuvant antibiotic therapy lowers the risks of treatment failure, abscess recurrence, hospitalisation, additional surgical procedures and pain during treatment; but increases the risk of overall gastrointestinal side effects (TMP-SMX and clindamycin) and diarrhoea (with clindamycin). The evidence regarding the effects of antibiotics on other important outcomes events (eg, death, invasive infections and sepsis) is less certain; however, these outcomes occurred very infrequently.

This evidence is most directly applicable to antibiotics with activity against MRSA (TMP-SMX and clindamycin), which appeared to be more effective at reducing the risk of treatment failure than antibiotics without activity against MRSA. Using standard criteria for evaluating the credibility of a subgroup effect, ${ }^{34}$ the MRSA active versus cephalosporin subgroup was one of a small number of prespecified hypotheses, has biologic plausibility, ${ }^{35}$ a low $P$ value in the test of interaction and the subgroup effect proved large. We were unable to examine if there was a similar effect on other outcomes because the RCTs that included antibiotics without MRSA activity did not report those outcomes. We judged the observed subgroup effect of moderate-to-high credibility.

The NMA of alternative antibiotic regimens could only be conducted for treatment failure. We found highquality evidence that there is no important difference in treatment failure between TMP-SMX and clindamycin, which is consistent with an RCT of patients with MRSA SSTIs. ${ }^{36}$ A single study found that TMP-SMX may confer a higher risk of abscess recurrence than clindamycin, which is consistent with a previous RCT of SSTIs. ${ }^{37}$ However, indirect evidence from our review suggests that this finding may be spurious: that study was also the only one of four where TMP-SMX did not reduce the risk of abscess recurrence compared with placebo-it did in all of the other studies and in the pooled effect. Moreover, when compared with no antibiotics, clindamycin did not appear to reduce the risk of abscess recurrence more than TMP-SMX. We did find high-quality evidence that TMP-SMX has a substantially lower risk of diarrhoea than clindamycin.

\section{Strengths and limitations}

Our study has several strengths. First, we systematically identified RCTs and rigorously collected and analysed the data. We conducted a small number of prespecified subgroup analyses to explore treatment heterogeneity, and a number of sensitivity analyses to examine robustness of effect estimates. Our review assessed both the effects of antibiotics versus no antibiotics, and the relative merit of different antibiotics, including a network meta-analysis that addressed the latter issue. The GRADE approach informed our assessment of the quality of evidence both in the comparison of antibiotics versus no antibiotics and the comparisons between antibiotics.

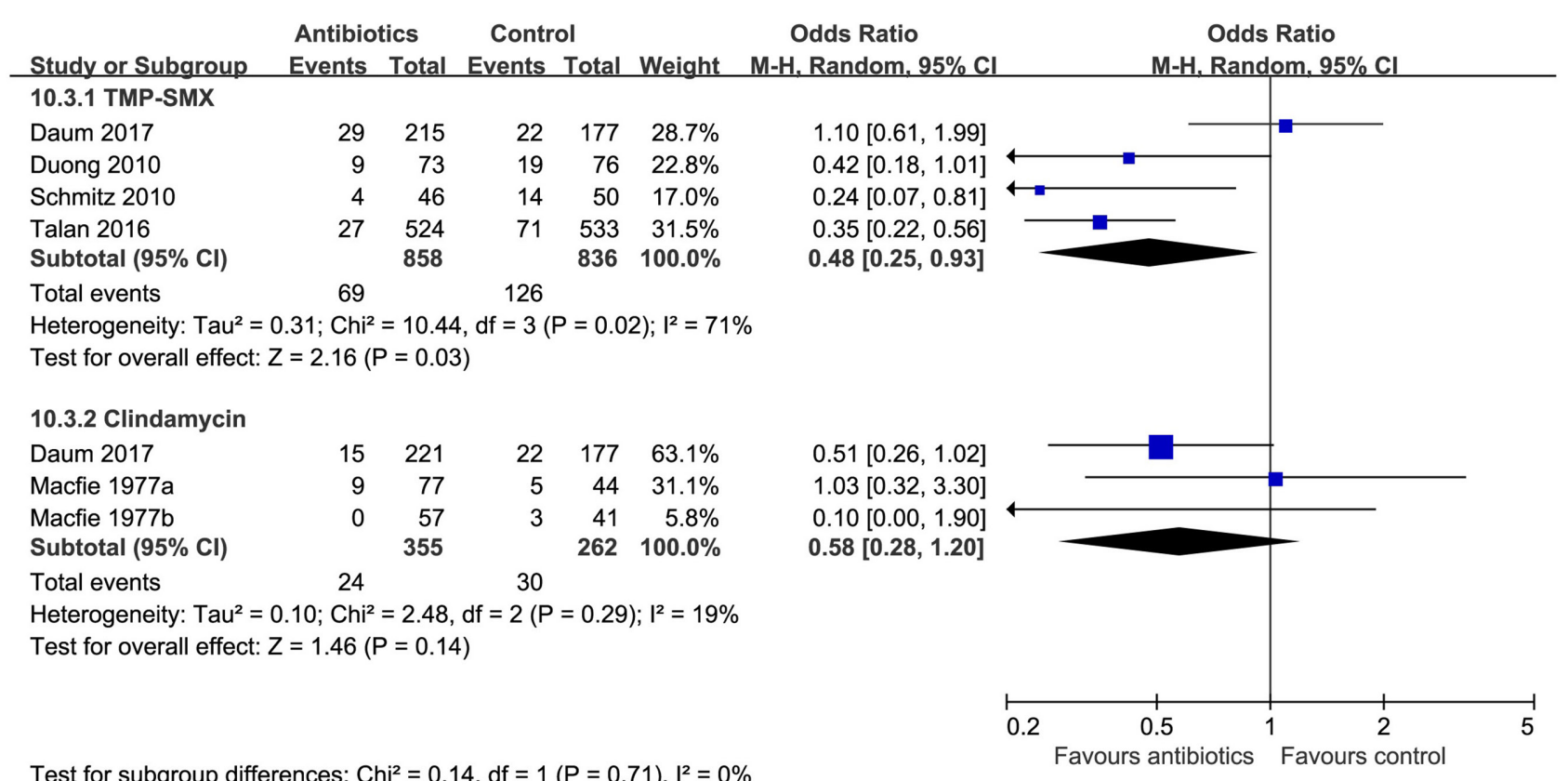

Figure 6 Subgroup analysis of recurrence by type of antibiotics (trimethoprim and sulfamethoxazole (TMP-SMX) vs clindamycin). 
Table 3 Summary of GRADE evidence profile of TMP-SMX/clindamycin vs no antibiotic

\begin{tabular}{|c|c|c|c|c|c|}
\hline \multirow[b]{2}{*}{ Outcome/timeframe } & \multirow[b]{2}{*}{ Study results and measurements } & \multicolumn{2}{|c|}{ Absolute effect estimates } & \multirow{2}{*}{$\begin{array}{l}\text { Certainty in effect } \\
\text { estimates (quality of } \\
\text { evidence) }\end{array}$} & \multirow[b]{2}{*}{ Plain text summary } \\
\hline & & No antibiotics & Antibiotics & & \\
\hline \multicolumn{6}{|l|}{ TMP-SMX vs no antibiotic } \\
\hline Sepsis/1 month & $\begin{array}{l}\text { OR } 7.24 \text { (95\% } \mathrm{Cl} 0.14 \text { to } 364.86) \\
\text { Based on data from } 1247 \text { patients in } \\
\text { one study } \\
\text { Follow-up } 49-63 \text { days }\end{array}$ & \multicolumn{2}{|c|}{$\begin{array}{l}\text { Difference: } 2 \text { more per } 1000 \\
\text { (95\% Cl } 3 \text { fewer-6 more) }\end{array}$} & $\begin{array}{l}\text { Moderate } \\
\text { Due to serious imprecision* }\end{array}$ & $\begin{array}{l}\text { Antibiotics probably do } \\
\text { not decrease the risk of } \\
\text { sepsis. }\end{array}$ \\
\hline Death/3 months & $\begin{array}{l}\text { OR } 0.98 \text { ( } 95 \% \mathrm{Cl} 0.06 \text { to } 15.68) \\
\text { Based on data from } 1763 \text { patients in } \\
\text { two studies } \\
\text { Follow-up } 30-90 \text { days }\end{array}$ & $\begin{array}{l}1 \\
\text { per } 1000 \\
\text { Difference: } 0 \text { fe } \\
(95 \% \mathrm{Cl} 4 \text { fewer }\end{array}$ & $\begin{array}{l}1 \\
\text { per } 1000 \\
\text { er per } 1000 \\
-4 \text { more) }\end{array}$ & $\begin{array}{l}\text { High } \\
\text { Borderline imprecision }\end{array}$ & $\begin{array}{l}\text { Antibiotics do not reduce } \\
\text { the risk of death. }\end{array}$ \\
\hline $\begin{array}{l}\text { Gastrointestinal side effects/ } \\
\text { while taking antibiotics }\end{array}$ & $\begin{array}{l}\text { OR } 1.28 \text { ( } 95 \% \mathrm{Cl} 1.04 \text { to } 1.58) \\
\text { Based on data from } 2124 \text { patients in } \\
\text { four studies } \\
\text { Follow-up } 30-90 \text { days }\end{array}$ & $\begin{array}{l}85 \\
\text { per } 1000 \\
\text { Difference: } 21 \mathrm{n} \\
(95 \% \mathrm{Cl} 3 \text { more }\end{array}$ & $\begin{array}{l}106 \\
\text { per } 1000 \\
43 \text { more) }\end{array}$ & $\begin{array}{l}\text { Moderate } \\
\text { Due to serious imprecision } †\end{array}$ & $\begin{array}{l}\text { TMP-SMX probably } \\
\text { increases the risk of } \\
\text { gastrointestinal side } \\
\text { effects. }\end{array}$ \\
\hline $\begin{array}{l}\text { Nausea/while taking } \\
\text { antibiotics }\end{array}$ & $\begin{array}{l}\text { OR } 1.49 \text { ( } 95 \% \text { Cl } 0.98 \text { to } 2.25) \\
\text { Based on data from } 1975 \text { patients in } \\
\text { three studies } \\
\text { Follow-up } 30-63 \text { days }\end{array}$ & $\begin{array}{l}24 \\
\text { per } 1000 \\
\text { Difference: } 11 n \\
(95 \% \mathrm{Cl} 0 \text { fewer }\end{array}$ & $\begin{array}{l}35 \\
\text { per } 1000 \\
\text { re per } 1000 \\
-28 \text { more) }\end{array}$ & $\begin{array}{l}\text { Moderate } \\
\text { Due to serious imprecision } \ddagger\end{array}$ & $\begin{array}{l}\text { TMP-SMX probably } \\
\text { increases the risk of } \\
\text { nausea. }\end{array}$ \\
\hline Diarrhoea/3 months & $\begin{array}{l}\text { OR } 0.92 \text { ( } 95 \% \mathrm{Cl} 0.7 \text { to } 1.22) \\
\text { Based on data from } 1912 \text { patients in } \\
\text { three studies } \\
\text { Follow-up } 30-63 \text { days }\end{array}$ & $\begin{array}{l}67 \\
\text { per } 1000 \\
\text { Difference: } 5 \text { fe } \\
(95 \% \mathrm{Cl} 19 \text { few }\end{array}$ & $\begin{array}{l}62 \\
\text { per } 1000 \\
\text { er per } 1000 \\
-14 \text { more) }\end{array}$ & $\begin{array}{l}\text { Moderate } \\
\text { Due to serious imprecision§ }\end{array}$ & $\begin{array}{l}\text { TMP-SMX probably does } \\
\text { not increase the risk of } \\
\text { diarrhoea. }\end{array}$ \\
\hline $\begin{array}{l}\text { Anaphylaxis/minutes to } \\
\text { days }\end{array}$ & $\begin{array}{l}\text { OR } 2.32(95 \% \mathrm{Cl} 0.67 \text { to } 8.06) \\
\text { Based on data from } 877 \text { patients in } \\
\text { three studies } \\
\text { Follow-up } 30-90 \text { days }\end{array}$ & $\begin{array}{l}7 \\
\text { per } 1000 \\
\text { Difference: } 8 \mathrm{~m} \\
(95 \% \mathrm{Cl} 2 \text { fewer }\end{array}$ & $\begin{array}{l}15 \\
\text { per } 1000 \\
\text { e per } 1000 \\
-44 \text { more) }\end{array}$ & $\begin{array}{l}\text { Low } \\
\text { Due to serious risk of bias } \\
\text { and imprecision }\end{array}$ & $\begin{array}{l}\text { Antibiotics probably } \\
\text { not increase the risk of } \\
\text { anaphylaxis. }\end{array}$ \\
\hline \multicolumn{6}{|l|}{ Clindamycin vs no antibiotics } \\
\hline $\begin{array}{l}\text { Gastrointestinal side effects/ } \\
\text { while taking antibiotics }\end{array}$ & $\begin{array}{l}\text { OR } 2.29(95 \% \mathrm{Cl} 1.35 \text { to } 3.88) \\
\text { Based on data from } 520 \text { patients in } \\
\text { one study } \\
\text { Follow-up } 30-90 \text { days }\end{array}$ & $\begin{array}{l}90 \\
\text { per } 1000 \\
\text { Difference: } 95 \mathrm{n} \\
(95 \% \mathrm{Cl} 28 \mathrm{mor}\end{array}$ & $\begin{array}{l}185 \\
\text { per } 1000 \\
\text { re per } 1000 \\
-187 \text { more) }\end{array}$ & High & $\begin{array}{l}\text { Clindamycin increases } \\
\text { the risk of gastrointestinal } \\
\text { side effects. }\end{array}$ \\
\hline $\begin{array}{l}\text { Nausea/while taking } \\
\text { antibiotics }\end{array}$ & $\begin{array}{l}\text { OR } 0.96(95 \% \mathrm{Cl} 0.31 \text { to } 3.02) \\
\text { Based on data from } 520 \text { patients in } \\
\text { one study } \\
\text { Follow-up } 30-63 \text { days }\end{array}$ & $\begin{array}{l}24 \\
\text { per } 1000 \\
\text { Difference: } 1 \mathrm{fe} \\
(95 \% \mathrm{Cl} 16 \mathrm{few}\end{array}$ & $\begin{array}{l}23 \\
\text { per } 1000 \\
\text { er per } 1000 \\
-45 \text { more) }\end{array}$ & $\begin{array}{l}\text { Moderate } \\
\text { Due to serious imprecision** }\end{array}$ & $\begin{array}{l}\text { Clindamycin may not } \\
\text { increase the risk of } \\
\text { nausea. }\end{array}$ \\
\hline Diarrhoea/3 months & $\begin{array}{l}\text { OR } 2.71 \text { ( } 95 \% \mathrm{Cl} 1.5 \text { to } 4.89 \text { ) } \\
\text { Based on data from } 520 \text { patients in } \\
\text { one study } \\
\text { Follow-up } 30-63 \text { days }\end{array}$ & $\begin{array}{l}67 \\
\text { per } 1000 \\
\text { Difference: } 96 \text { n } \\
\text { (95\% Cl } 30 \text { mor }\end{array}$ & $\begin{array}{l}162 \\
\text { per } 1000 \\
\text { re per } 1000 \\
-193 \text { more) }\end{array}$ & High & $\begin{array}{l}\text { Clindamycin increases } \\
\text { the risk of diarrhoea. }\end{array}$ \\
\hline $\begin{array}{l}\text { Anaphylaxis/minutes to } \\
\text { days }\end{array}$ & $\begin{array}{l}\text { OR } 2.17 \text { ( } 95 \% \mathrm{Cl} 0.62 \text { to } 7.58) \\
\text { Based on data from } 520 \text { patients in } \\
\text { one study } \\
\text { Follow-up } 30-90 \text { days }\end{array}$ & $\begin{array}{l}12 \\
\text { per } 1000 \\
\text { Difference: } 14 \mathrm{n} \\
\text { (95\% Cl } 5 \text { fewe }\end{array}$ & $\begin{array}{l}26 \\
\text { per } 1000 \\
\text { re per } 1000 \\
-72 \text { more) }\end{array}$ & $\begin{array}{l}\text { Low } \\
\text { Due to serious risk of bias } \\
\text { and imprecisiont† }\end{array}$ & $\begin{array}{l}\text { Antibiotics probably } \\
\text { not increase the risk of } \\
\text { anaphylaxis. }\end{array}$ \\
\hline
\end{tabular}

*Imprecision: Serious. Due to serious imprecision.

†Imprecision: serious. Cl approaches no effect.

†Imprecision: serious. $\mathrm{Cl}$ approaches no effect.

§Imprecision: serious. Cl approaches no effect.

qRisk of bias: serious. Selective outcome reporting: studies without any events are likely to have not reported this outcome, leading to overestimation of risk;

imprecision: serious. Few events. Not all studies reported anaphylaxis.

**Imprecision: very serious. $\mathrm{Cl}$ approaches no effect.

††Risk of bias: serious. Selective outcome reporting: studies without any events are likely to have not reported this outcome, leading to overestimation of risk; imprecision: serious. Few events. Not all studies reported anaphylaxis.

GRADE, Grading of Recommendations Assessment, Development and Evaluation; TMP-SMX, trimethoprim and sulfamethoxazole.

The results are primarily limited by the available studies. Four of the RCTs were published $>30$ years ago and surgical treatments as well as antibiotic resistance patterns have changed. The results and interpretation did not change when these trials were excluded from the analyses. Although we planned a number of hypotheses for exploring potential heterogeneity across studies, sufficient data were available only for treatment failure, recurrence within 1 month and for three hypotheses $(\geq 18 \mathrm{vs}<18$ years, antibiotics with vs without MRSA activity, TMP-SMX vs clindamycin). In addition, the definition of outcomes varied among included trials.

Clinicians should consider local rates of CA-MRSA resistance to clindamycin and TMP-SMX; antibiotics 


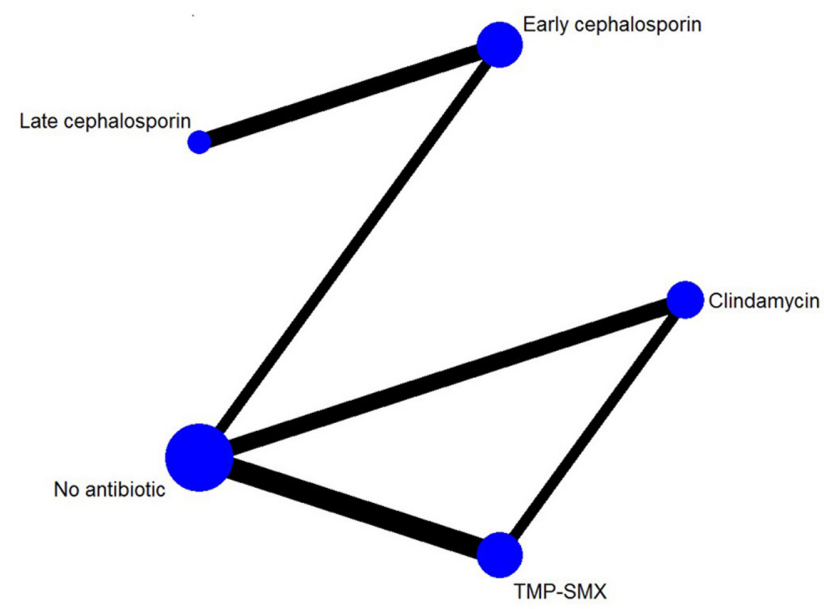

Figure 7 Network of included randomised controlled trials with available direct comparisons for treatment failure within 1 month. TMP-SMX, trimethoprim and sulfamethoxazole.

will be less effective in areas with a substantial risk of resistance. Most of included studies involved patients treated in an emergency department. Considering the characteristics of involved patients and medical conditions may differ between emergency department and GPs, antibiotics may confer an even smaller benefit in
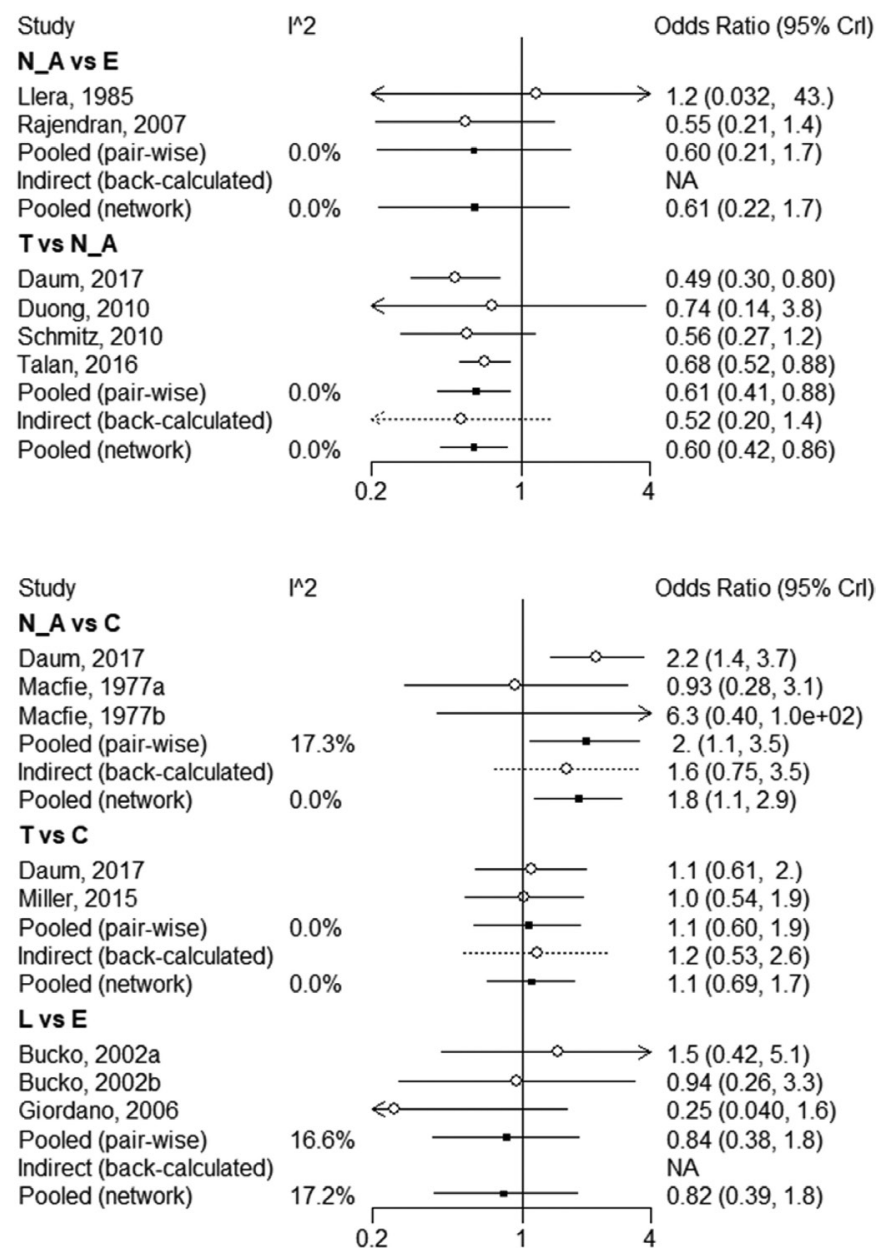

Figure 8 Forest plot of network meta-analysis results for treatment failure within 1 month.

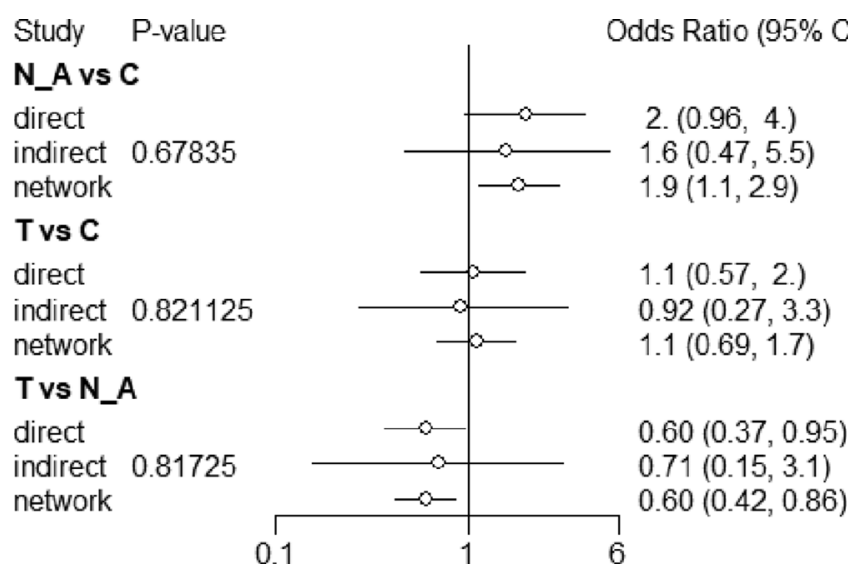

Figure 9 Assessment of network consistency, for all comparisons for which pairwise and indirect estimates were possible.

patients who present to their GP. This evidence does not apply to pustules and papules. Moreover, rare adverse events are unlikely to be observed in RCTs. Important but rare adverse events include anaphylaxis, C. difficile infection (especially with clindamycin ${ }^{38}$ ) and StevensJohnson syndrome or toxic epidermal necrolysis (especially with TMP-SMX) ${ }^{39}$ Only one trial ${ }^{10}$ reported rate of serious invasive infection $(0.2 \%-0.4 \%)$; however, the trial was underpowered to detect differences of this very rare but potentially fatal event.

\section{Comparison with other studies}

Two systematic reviews and meta-analyses have assessed the effect of adjunctive antibiotics versus no antibiotics in the treatment of skin abscess. ${ }^{8} 40$ One systematic review ${ }^{40}$ included 4 trials of 589 patients failed to detect a benefit of antibiotics on clinical cure (OR 1.17, 95\% CI 0.70 to 1.95 ) and recurrence (RD 10 more per 100, 95\% CI 2 fewer to 22 more). The other ${ }^{8}$ included five RCTs and seven observational studies also failed to detect benefit with antibiotics on clinical cure rates (RR $1.03,95 \%$ CI 0.97 to 1.08 ).

The difference in results is attributable to two recent large RCTs, with increased power to detect small-to-moderate effects. ${ }^{910}$ Another reason that previous systematic reviews failed to show benefit is that the relative weight of trials comparing cephalosporins with placebo, which likely do not confer a benefit, was greater. ${ }^{35}$ The benefits of antibiotics are modest, and they come with an important risk of adverse effects. Some well-described rare but serious adverse effects such as community-acquired $C$. difficile infection (especially with clindamycin), hypersensitivity (especially with TMP-SMX) and life-threatening skin reactions such as toxic epidermal necrolysis and StevensJohnson syndrome (especially with TMP-SMX) would not occur frequently enough to be detected with RCTs, but are important considerations nonetheless. It is therefore likely that some fully informed patients will choose antibiotics and others will decline. 
Table 4 Risk difference per 1000 patients of various antibiotics from the network meta-analysis for treatment failure within 1 month

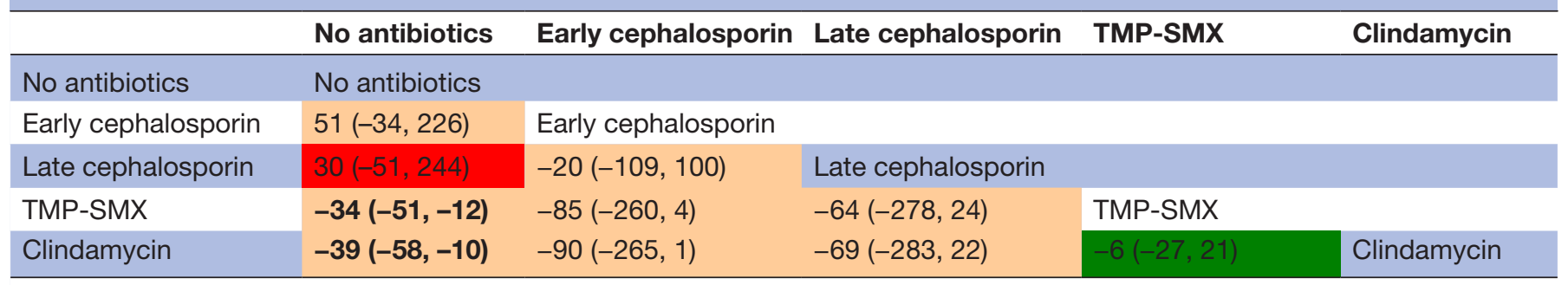

Each number is a risk difference, per 1000 patients, and 95\% credible interval. The rows are the reference category: a risk difference $<0$ favours the row. Green shading=high certainty; orange shading=moderate certainty; red shading=low certainty. Based on the median treatment failure rate in the no antibiotics arms, we assume that the baseline risk of treatment failure without antibiotics is 90 per 1000 patients.

TMP-SMX, trimethoprim and sulfamethoxazole.

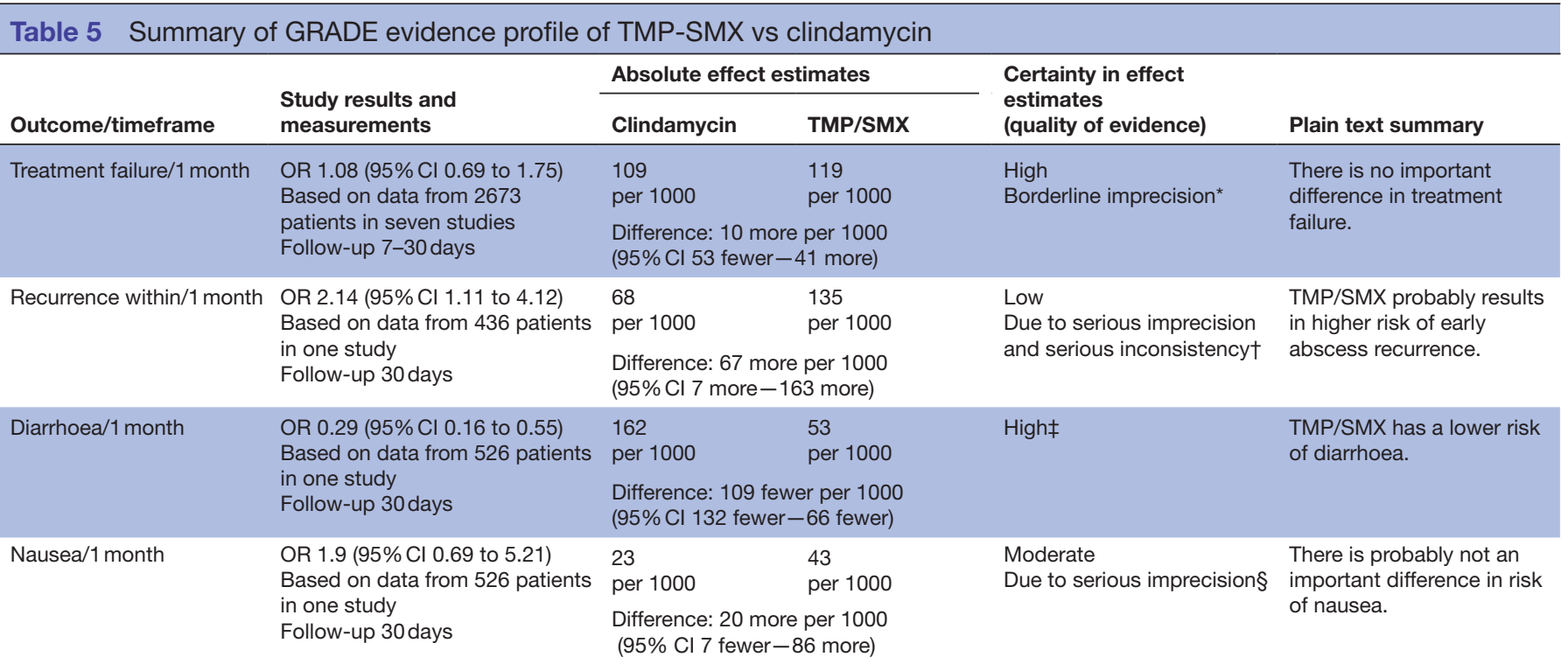

*Imprecision: no serious. Borderline wide Cls.

†Imprecision: serious. Data from one study only; $\mathrm{Cl}$ approaches no difference; inconsistency: serious. The results are not consistent with the subgroup analysis, nor with the indirect evidence.

fImprecision: no serious. Direct data from one study only. However, we did not rate down for imprecision because of high certainty indirect evidence from other conditions that clindamycin has a higher risk of diarrhoea than TMP/SMX.

§Imprecision: serious. Data from one study only; wide Cls.

GRADE, Grading of Recommendations Assessment, Development and Evaluation; TMP-SMX, trimethoprim and sulfamethoxazole.

\section{Table 6 Summary of GRADE evidence profile of TMP-SMX vs early cephalosporins}

\begin{tabular}{|c|c|c|c|c|c|}
\hline \multirow[b]{2}{*}{ Outcome/timeframe } & \multirow{2}{*}{$\begin{array}{l}\text { Study results and } \\
\text { measurements }\end{array}$} & \multicolumn{2}{|c|}{ Absolute effect estimates } & \multirow{2}{*}{$\begin{array}{l}\text { Certainty in effect } \\
\text { estimates (quality of } \\
\text { evidence) }\end{array}$} & \multirow[b]{2}{*}{ Plain text summary } \\
\hline & & Cephalosporins & TMP/SMX & & \\
\hline \multirow[t]{2}{*}{ Treatment failure/1 month } & \multirow{2}{*}{$\begin{array}{l}\text { OR } 0.42 \text { ( } 95 \% \mathrm{Cl} 0.12 \text { to } 1.07 \text { ) } \\
\text { Based on data from } 1436 \\
\text { patients in five studies } \\
\text { Follow-up } 7 \text { to } 21 \text { days }\end{array}$} & $\begin{array}{l}280 \\
\text { per } 1000\end{array}$ & $\begin{array}{l}119 \\
\text { per } 1000\end{array}$ & \multirow[t]{2}{*}{$\begin{array}{l}\text { Moderate } \\
\text { Due to serious imprecision* }\end{array}$} & \multirow{2}{*}{$\begin{array}{l}\text { TMP/SMX probably } \\
\text { reduces the risk of } \\
\text { treatment failure. }\end{array}$} \\
\hline & & \multicolumn{2}{|c|}{$\begin{array}{l}\text { Difference: } 162 \text { fewer per } 1000 \\
\text { (95\% Cl } 392 \text { fewer to } 7 \text { more) }\end{array}$} & & \\
\hline
\end{tabular}

*Imprecision: serious. $\mathrm{Cl}$ includes no difference.

GRADE, Grading of Recommendations Assessment, Development and Evaluation; TMP-SMX, trimethoprim and sulfamethoxazole.

\section{CONCLUSIONS}

Based on moderate-to-high quality evidence, antibiotics provide a modest reduction in the risk of treatment failure, recurrence, additional surgical procedures and hospitalisation, and reduce pain during treatment. Antibiotics increase the risk of gastrointestinal side effects, such as nausea (TMP-SMX) and diarrhoea (clindamycin). This evidence is most applicable to TMP-SMX and clindamycin; cephalosporins are probably less or not effective. High-quality evidence demonstrated that TMP-SMX and clindamycin have similar effects on treatment failure, but clindamycin has a substantially higher risk of diarrhoea. The decision whether or not to use antibiotics should take into 
Table 7 Summary of GRADE evidence profile of clindamycin vs early cephalosporins

\begin{tabular}{|c|c|c|c|c|c|}
\hline \multirow[b]{2}{*}{ Outcome/timeframe } & \multirow[b]{2}{*}{ Study results and measurements } & \multicolumn{2}{|c|}{ Absolute effect estimates } & \multirow{2}{*}{$\begin{array}{l}\text { Certainty in effect estimates } \\
\text { (quality of evidence) }\end{array}$} & \multirow[b]{2}{*}{ Plain text summary } \\
\hline & & Cephalosporins & Clindamycin & & \\
\hline \multirow[t]{2}{*}{ Treatment failure/1 month } & \multirow{2}{*}{$\begin{array}{l}\text { OR } 0.39 \text { ( } 95 \% \mathrm{Cl} 0.11 \text { to } 1.02) \\
\text { Based on data from } 1572 \text { patients } \\
\text { in five studies } \\
\text { Follow-up } 7-21 \text { days }\end{array}$} & $\begin{array}{l}280 \\
\text { per } 1000\end{array}$ & $\begin{array}{l}109 \\
\text { per } 1000\end{array}$ & $\begin{array}{l}\text { Moderate } \\
\text { Due to serious imprecision* }\end{array}$ & \multirow{2}{*}{$\begin{array}{l}\text { Clindamycin probably } \\
\text { reduces the risk of } \\
\text { treatment failure. }\end{array}$} \\
\hline & & \multicolumn{2}{|c|}{$\begin{array}{l}\text { Difference: } 171 \text { fewer per } 1000 \\
\text { (95\% Cl } 401 \text { fewer to } 2 \text { more) }\end{array}$} & & \\
\hline
\end{tabular}

*Imprecision: serious. $\mathrm{Cl}$ includes no difference.

GRADE, Grading of Recommendations Assessment, Development and Evaluation.

account local MRSA resistance patterns, individual patient clinical factors (eg, severity of infection, immunocompromised state) and individual values and preferences (eg, a strong desire to avoid diarrhoea).

Acknowledgements The authors thank members of the BMJ Rapid Recommendations panel for critical feedback on outcome selection, subgroup selection, GRADE judgments and manuscript feedback. The authors thank Rachel Couban for helping developing the search strategy, Toshiaki A Furukawa for helping finding full text and Xu Zhou for screening of a Japanese report.

Contributors WW, WC, YL and RACS contributed equally to this work. RACS, GHG, XS and WW conceived the study. XS and WW had full access to all of the data in the study, and take responsibility for the integrity of the data and the accuracy of the data analysis. WW and RACS designed the search strategy. WW, WC, YL and LL screened abstracts and full texts, and acquired the data and judged risk of bias in the studies. WW, RACS and JPDM performed the data analysis. WW, WC and YL wrote the first draft of the manuscript. RACS, LL, XS, JPDM, GHG critically revised the manuscript. All authors have approved the manuscript.

Funding XS was supported by the National Natural Science Foundation of China (grant no. 71573183) and 'Thousand Youth Talents Plan' of China (grant no. D1024002).

Competing interests None declared.

Patient consent Not required.

Provenance and peer review Not commissioned; externally peer reviewed.

Data sharing statement Extra data are available in the publication of the BMJ Rapid Recommendation in MAGICapp.

Open Access This is an Open Access article distributed in accordance with the Creative Commons Attribution Non Commercial (CC BY-NC 4.0) license, which permits others to distribute, remix, adapt, build upon this work non-commercially, and license their derivative works on different terms, provided the original work is properly cited and the use is non-commercial. See: http://creativecommons.org/ licenses/by-nc/4.0/

(C) Article author(s) (or their employer(s) unless otherwise stated in the text of the article) 2018. All rights reserved. No commercial use is permitted unless otherwise expressly granted.

\section{REFERENCES}

1. Miller LG, Eisenberg DF, Liu H, et al. Incidence of skin and soft tissue infections in ambulatory and inpatient settings, 2005-2010. BMC Infect Dis 2015;15:362.

2. Edelsberg J, Taneja C, Zervos M, et al. Trends in US hospital admissions for skin and soft tissue infections. Emerg Infect Dis 2009;15:1516-8.

3. Hersh AL, Chambers HF, Maselli JH, et al. National trends in ambulatory visits and antibiotic prescribing for skin and soft-tissue infections. Arch Intern Med 2008;168:1585-91.

4. Moran GJ, Krishnadasan A, Gorwitz RJ, et al. Methicillin-resistant S. aureus infections among patients in the emergency department. $N$ Engl J Med 2006;355:666-74.

5. Montravers P, Snauwaert A, Welsch C. Current guidelines and recommendations for the management of skin and soft tissue infections. Curr Opin Infect Dis 2016;29:131-8.

6. Esposito S, Bassetti M, Borre' S, et al. Diagnosis and management of skin and soft-tissue infections (SSTI): a literature review and consensus statement on behalf of the Italian Society of Infectious
Diseases and International Society of Chemotherapy. $J$ Chemother 2011;23:251-62.

7. Stevens DL, Bisno AL, Chambers HF, et al. Practice guidelines for the diagnosis and management of skin and soft tissue infections: 2014 update by the infectious diseases society of America. Clin Infect Dis 2014;59:147-59.

8. Fahimi J, Singh A, Frazee BW. The role of adjunctive antibiotics in the treatment of skin and soft tissue abscesses: a systematic review and meta-analysis. CJEM 2015;17:420-32.

9. Daum RS, Miller LG, Immergluck $L$, et al. A placebo-controlled trial of antibiotics for smaller skin abscesses. N Engl J Med 2017;376:2545-55.

10. Talan DA, Mower WR, Krishnadasan A, et al. TrimethoprimSulfamethoxazole versus Placebo for Uncomplicated Skin Abscess. N Engl J Med 2016;374:823-32.

11. Siemieniuk RA, Agoritsas $\mathrm{T}$, Macdonald $\mathrm{H}$, et al. Introduction to $\mathrm{BM}$ Rapid Recommendations. BMJ 2016;354:i5191.

12. Moher D, Liberati A, Tetzlaff $J$, et al. Preferred reporting items for systematic reviews and meta-analyses: the PRISMA statement. Int $J$ Surg 2010;8:336-41.

13. Hutton B, Salanti G, Caldwell DM, et al. The PRISMA extension statement for reporting of systematic reviews incorporating network meta-analyses of health care interventions: checklist and explanations. Ann Intern Med 2015;162:777-84.

14. Vermandere $M$, Aergeerts $B$, Agoritsas $T$, et al. Antibiotics for uncomplicated skin abscesses: a clinical practice guideline. BMJ. In Press.

15. Akl EA, Sun X, Busse JW, et al. Specific instructions for estimating unclearly reported blinding status in randomized trials were reliable and valid. J Clin Epidemiol 2012;65:262-7.

16. Higgins JP, Altman DG, Gøtzsche PC, et al. The Cochrane Collaboration's tool for assessing risk of bias in randomised trials. BMJ 2011;343:d5928.

17. Evidence Partners. Methodological Resources. https://www. evidencepartners.com/resources/methodological-resources/

18. Gelman A, Rubin DB. Inference from Iterative Simulation Using Multiple Sequences. Statist Sci 1992;7:457-72.

19. van Valkenhoef $\mathrm{G}$, Dias $\mathrm{S}$, Ades $\mathrm{AE}$, et al. Automated generation of node-splitting models for assessment of inconsistency in network meta-analysis. Res Synth Methods 2016;7:80-93.

20. van Valkenhoef G, Lu G, de Brock B, et al. Automating network meta-analysis. Res Synth Methods 2012;3:285-99.

21. Guyatt GH, Oxman AD, Vist GE, et al. GRADE: an emerging consensus on rating quality of evidence and strength of recommendations. BMJ 2008;336:924-6.

22. Puhan MA, Schünemann HJ, Murad MH, et al. A GRADE Working Group approach for rating the quality of treatment effect estimates from network meta-analysis. BMJ 2014;349:95630.

23. Guyatt GH, Ebrahim S, Alonso-Coello P, et al. GRADE guidelines 17: assessing the risk of bias associated with missing participant outcome data in a body of evidence. J Clin Epidemiol 2017;87:14-22

24. Duong M, Markwell S, Peter J, et al. Randomized, controlled trial of antibiotics in the management of community-acquired skin abscesses in the pediatric patient. Ann Emerg Med 2010;55:401-7.

25. Llera JL, Levy RC. Treatment of cutaneous abscess: a double-blind clinical study. Ann Emerg Med 1985;14:15-19.

26. Schmitz GR, Bruner D, Pitotti R, et al. Randomized controlled trial of trimethoprim-sulfamethoxazole for uncomplicated skin abscesses in patients at risk for community-associated methicillin-resistant Staphylococcus aureus infection. Ann Emerg Med 2010;56:283-7.

27. Rajendran PM, Young D, Maurer T, et al. Randomized, double-blind, placebo-controlled trial of cephalexin for treatment of uncomplicated skin abscesses in a population at risk for community-acquired methicillin-resistant Staphylococcus aureus infection. Antimicrob Agents Chemother 2007;51:4044-8. 
28. Macfie J, Harvey J. The treatment of acute superficial abscesses. $\mathrm{Br}$ J Surg 1977;64:264-6.

29. Bucko AD, Hunt BJ, Kidd SL, et al. Randomized, double-blind, multicenter comparison of oral cefditoren 200 or $400 \mathrm{mg} \mathrm{BID}$ with either cefuroxime $250 \mathrm{mg}$ BID or cefadroxil $500 \mathrm{mg}$ BID for the treatment of uncomplicated skin and skin-structure infections. Clin Ther 2002;24:1134-47.

30. Giordano PA, Elston D, Akinlade BK, et al. Cefdinir vs. cephalexin for mild to moderate uncomplicated skin and skin structure infections in adolescents and adults. Curr Med Res Opin 2006;22:2419-28.

31. Montero L. A comparative study of the efficacy, safety and tolerability of azithromycin and cefaclor in the treatment of children with acute skin and/or soft tissue infections. J Antimicrob Chemother 1996;37(Suppl C):125-31.

32. Miller LG, Daum RS, Creech CB, et al. Clindamycin versus trimethoprim-sulfamethoxazole for uncomplicated skin infections. $N$ Engl J Med 2015;372:1093-103.

33. Keiichi F, Eiichiro N, Hisashi T, et al. Clinical Evaluation of Cefadroxil in the Treatment of Superficial Suppurative Skin and Soft Tissue Infections -A Double-blind Study Comparing to L-Cephalexin. Rinsho Hyoka 1982;10:175-200.
34. Sun X, Briel M, Walter SD, et al. Is a subgroup effect believable? Updating criteria to evaluate the credibility of subgroup analyses. BMJ 2010;340:c117.

35. Daum RS. Clinical practice. Skin and soft-tissue infections caused by methicillin-resistant Staphylococcus aureus. N Engl J Med 2007;357:380-90.

36. Hyun DY, Mason EO, Forbes A, et al. Trimethoprim-sulfamethoxazole or clindamycin for treatment of community-acquired methicillinresistant Staphylococcus aureus skin and soft tissue infections. Pediatr Infect Dis J 2009;28:57-9.

37. Williams DJ, Cooper WO, Kaltenbach LA, et al. Comparative effectiveness of antibiotic treatment strategies for pediatric skin and soft-tissue infections. Pediatrics 2011;128:e479-e87.

38. Deshpande A, Pasupuleti V, Thota P, et al. Community-associated Clostridium difficile infection and antibiotics: a meta-analysis. $J$ Antimicrob Chemother 2013;68:1951-61.

39. Roujeau JC, Kelly JP, Naldi L, et al. Medication use and the risk of Stevens-Johnson syndrome or toxic epidermal necrolysis. N Engl $J$ Med 1995;333:1600-7.

40. Singer AJ, Thode HC. Systemic antibiotics after incision and drainage of simple abscesses: a meta-analysis. Emerg Med $J$ 2014;31:576-8. 